\title{
A Novel Multi-Period Mixed-Integer Linear Optimization Model for Optimal Distribution of Byproduct Gases, Steam and Power in an Iron and Steel Plant
}

Dol:

10.1016/j.energy.2017.10.122

\section{Document Version}

Accepted author manuscript

Link to publication record in Manchester Research Explorer

Citation for published version (APA):

Zeng, Y., Xiao, X., Li, J., Sun, L., Floudas, C. A., \& Li, H. (2017). A Novel Multi-Period Mixed-Integer Linear Optimization Model for Optimal Distribution of Byproduct Gases, Steam and Power in an Iron and Steel Plant. Energy, 143, 881-899. https://doi.org/10.1016/j.energy.2017.10.122

\section{Published in:}

Energy

\section{Citing this paper}

Please note that where the full-text provided on Manchester Research Explorer is the Author Accepted Manuscript or Proof version this may differ from the final Published version. If citing, it is advised that you check and use the publisher's definitive version.

\section{General rights}

Copyright and moral rights for the publications made accessible in the Research Explorer are retained by the authors and/or other copyright owners and it is a condition of accessing publications that users recognise and abide by the legal requirements associated with these rights.

\section{Takedown policy}

If you believe that this document breaches copyright please refer to the University of Manchester's Takedown Procedures [http://man.ac.uk/04Y6Bo] or contact uml.scholarlycommunications@manchester.ac.uk providing relevant details, so we can investigate your claim.

\section{OPEN ACCESS}




\section{Accepted Manuscript}

A Novel Multi-Period Mixed-Integer Linear Optimization Model for Optimal Distribution of Byproduct Gases, Steam and Power in an Iron and Steel Plant

Yujiao Zeng, Xin Xiao, Jie Li, Li Sun, Christodoulos A. Floudas, Hechang Li

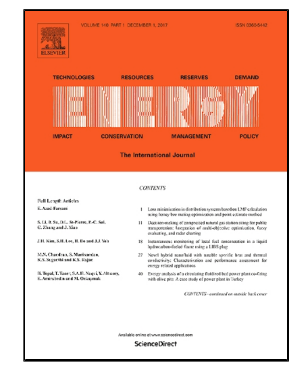

PII:

S0360-5442(17)31828-5

DOI:

10.1016/j.energy.2017.10.122

Reference:

EGY 11766

To appear in:

Energy

Received Date:

08 March 2017

Revised Date:

16 October 2017

Accepted Date:

26 October 2017

Please cite this article as: Yujiao Zeng, Xin Xiao, Jie Li, Li Sun, Christodoulos A. Floudas, Hechang $\mathrm{Li}$, A Novel Multi-Period Mixed-Integer Linear Optimization Model for Optimal Distribution of Byproduct Gases, Steam and Power in an Iron and Steel Plant, Energy (2017), doi: 10.1016/j. energy.2017.10.122

This is a PDF file of an unedited manuscript that has been accepted for publication. As a service to our customers we are providing this early version of the manuscript. The manuscript will undergo copyediting, typesetting, and review of the resulting proof before it is published in its final form. Please note that during the production process errors may be discovered which could affect the content, and all legal disclaimers that apply to the journal pertain. 


\section{Highlights}

- Novel multiperiod MILP model for optimal distribution of byproduct gases, steam and power

- Correct modeling of burner switches with fewer binary variables allowing turning on/off at a time

- Introduce key practical features in byproduct gas, steam and power generation and distribution

- Reduce total operating cost by $6 \%$ compared to that from the real operation 


\title{
A Novel Multi-Period Mixed-Integer Linear Optimization Model for Optimal Distribution of Byproduct Gases, Steam and Power in an Iron and Steel Plant
}

\author{
Yujiao Zeng, ${ }^{1}$ Xin Xiao, ${ }^{1 *}$ Jie Li, ${ }^{2 \dagger}$ Li Sun, ${ }^{2}$ Christodoulos A. Floudas ${ }^{3,4}$ and Hechang $\mathrm{Li}^{5}$ \\ ${ }^{1}$ Division of Environment Technology and Engineering, Institute of Process Engineering, Chinese \\ Academy of Sciences, Beijing, 100190 P. R. China \\ ${ }^{2}$ School of Chemical Engineering and Analytical Science, The University of Manchester, \\ Manchester, M13 9PL UK \\ ${ }^{3}$ Department of Chemical Engineering, Texas A\&M University, College Station, TX 77843 USA \\ ${ }^{4}$ Texas Energy Institute, Texas A\&M University, College Station, TX 77843 USA \\ ${ }^{5}$ Department of Energy and Environment, Shougang Jingtang United Iron \& Steel Co. Ltd., \\ Tangshan, 063200 P.R. China
}

\begin{abstract}
Byproduct gases, steam and electricity play an important role in providing energy for production units in the iron and steel industry. Optimal distribution of byproduct gases, steam and electricity in an iron and steel plant can significantly decrease energy cost and reduce $\mathrm{CO}_{2}$ emissions. However, such optimal distribution is not trivial because it involves many production units, steam turbines, combined heat and power units, and waste heat and energy recovery units, and several realistic operational features such as byproduct gas mixing, byproduct gas level control in dedicated gasholders, different levels of steam requirement, minimum heating and energy requirement, and maximum allowable burner switches, resulting in a large complex combinatorial problem. In this paper, we develop a novel multi-period mixed-integer linear programming model for optimal distribution of byproduct gases, steam, and power in an iron and steel plant. The consuming rates of byproduct gases are variable. Different byproduct gases are allowed to be mixed to satisfy minimum heating and energy requirement of production units. The steam is specifically classified as high, medium and low pressure. New binary variables are introduced to determine electricity purchase or sale decision with each having different price. The burner switching operation is correctly modeled with fewer binary variables allowing turning on and off at any time. Several important practical features such as fuel selection, gasholder level control, ramp rate variation, piecewise constant generation rates of byproduct gases, and piecewise constant demand profiles of byproduct gases, steam and electricity are also incorporated. The computational results demonstrate that the optimal operating cost is obtained within 2 CPU seconds for an industrial example using the proposed model, which is reduced by $6 \%$ compared to that from actual operation.
\end{abstract}

Keywords: Multi-period, mixed integer linear programming (MILP), optimization, energy efficiency, iron and steel

\footnotetext{
* To whom correspondence should be addressed. xxiao@ipe.ac.cn. Tel: +86 (0) 10-62566737

† To whom correspondence should be addressed. jie.li-2@manchester.ac.uk. Tel: +44 (0) 1613068622
} 


\section{Introduction}

The iron and steel industry is one of the energy-intensive industries with high $\mathrm{CO}_{2}$ emissions. As reported, the energy consumption in the iron and steel sector can account for about $18 \%$ of the total energy consumption from worldwide industrial sectors [1]. The $\mathrm{CO}_{2}$ emission from the iron and steel sector can account for about $7 \%$ of the total $\mathrm{CO}_{2}$ emission in the world [2]. With increasing concerns over energy scarcity and climate change [3] the iron and steel industry is facing great pressure to increase profit margin, improve energy efficiency and reduce $\mathrm{CO}_{2}$ emissions, which drives to seek advanced techniques to improve their planning operations. Optimal planning of various operations in the iron and steel industry through advanced mathematical programming approach especially mixedinteger approach offers significant opportunities for such improvement.

In a typical iron and steel plant, byproduct gases, steam and electricity play an important role in providing energy to production units such as sintering furnaces, coke ovens, blast furnaces, basic oxygen furnaces, cold rolling mills and hot rolling mills. As shown in Figure 1, byproduct gases such as coke oven gas (COG), blast furnace gas (BFG), and Linze-Donawitz gas (LDG) generated from coke ovens, blast furnaces, and basic oxygen furnaces are provided for production units, boilers for heat and steam generation, and combined heat and power (CHP) units for heat and power generation, or stored in their dedicated gasholders. Excess byproduct gases have to be sent to gas flare system for flaring, resulting in energy loss and $\mathrm{CO}_{2}$ emissions. Waste heat from production units is recovered in waste heat and energy recovery units for steam and power generation. Some steam generated from boilers are provided to steam turbines for power generation and low level steam extraction. The remaining steam from boilers and the steam from turbines, and CHP units, and waste heat and energy recovery units are provided for production units to satisfy their heat and energy requirement. Excess steam is released to the atmosphere without efficient utilization, resulting in large energy waste. The electricity generated from steam turbines, CHP units, and waste heat and energy recovery units are provided for production units to meet their electricity demand. Excess electricity is sold to the grid for additional profit, whilst insufficient electricity is purchased from the grid introducing additional energy cost. Therefore, optimal distribution of byproduct gases, steam and power in an iron and steel plant can offer efficient utilization of byproduct gases, steam and electricity, significantly reducing energy cost and $\mathrm{CO}_{2}$ emissions. However, achieving their optimal distribution is not trivial since it involves many production units, fuel boilers, steam turbines, and other steam and power cogeneration units such as CHP units, and waste heat and energy recovery units, which are not considered in the existing models. More important, generation rates of byproduct gases and demands of byproduct gases, steam and electricity from production units vary from time to time, increasing the complexity of achieving their optimal distribution. The decisions on the number of burner switches in a boiler and on the electricity purchase or sale at a time make the problem a complex combinatorial problem. 
Many research efforts have been made on design, planning, and scheduling of production processes such as blast furnace iron-making process [4], steelmaking and continuous casting process [5], and steelmaking continuous casting-hot rolling process [6] without considering energy optimization. Early work considering energy issues in an iron and steel plant mainly focused on the development of methods and models for the analysis and evaluation of energy consumption [7, 8], historical energy efficiency $[9,10]$, and energy saving potential $[11,12]$ in an iron and steel plant without optimization. For example, Arens et al. [7] analysed energy consumption from 1991 to 2007 in the German iron and steel industry. Ansari et al. [8] developed a system dynamic model to estimate energy consumption under various production and export scenarios for the Iranian iron and steel industry in the next 20 years. Zhang et al. [9] proposed the Cobb-Douglas type production model to estimate the impact of energy saving technologies on the productive efficiency during 1990-2000 in the Chinese iron and steel industry. He et al. [10] used the data envelopment analysis model and the Malmquist Productivity Index to evaluate energy efficiency and product change during 2001-2008 in the Chinese iron and steel industry. Hasanbeigi et al. [11] developed a bottom-up model based conservation supply curve method to estimate energy efficiency improvement and potential $\mathrm{CO}_{2}$ reduction from 2010-2013 in the Chinese iron and steel industry. Lin et al. [12] used the energyeconomy co-integration method and scenario analysis to estimate energy conservation potential for the Chinese iron and steel industry in 2020.

The research related to energy optimization in an iron and steel plant mainly focused on the optimal supply or distribution of byproduct gases in gasholders and boilers since byproduct gases are one of the main energy sources in an iron and steel plant [13, 14]. Akimoto et al. [13] developed a mixed integer linear programming (MILP) model for optimal supply of byproduct gases to boilers in a joint electric power plant. Several realistic operational features such as byproduct gas mixing, normal gasholder level control, fuel switching, combustion-of-gas-only operation, and simultaneous changeover of multiple boilers were incorporated into their model. Kim et al. [14] proposed a novel MILP model for optimal distribution of byproduct gases in gasholders and boilers in an iron and steel plant. Steam and power generation from boilers and turbines were considered to minimize oil consumption. The deviations of gasholder levels were minimized to be maintained in the normal levels. Detailed burner switching operations were also incorporated into their model.

All of these above efforts related with byproduct gas supply or distribution have several important disadvantages. First, the amount of byproduct gases consumed in production units is assumed to be known a prior. The optimal distribution of byproduct gases only in boilers and gasholders without involving production units is determined, resulting in suboptimal distribution of byproduct gases in an iron and steel plant. Second, only the distribution of byproduct gases or steam is optimized, ignoring simultaneous optimization of byproduct gases, steam and electricity 
distribution. Third, other steam and electricity generation equipment like CHP, and waste heat and energy recovery units which are often used in an iron and steel plant are not integrated. Fourth, different levels of steam including high-pressure, medium-pressure, and low-pressure steam are not taken into account. Fifth, most of them do not allow electricity purchase option from the grid. Sixth, the modeling of burner switching operations is misunderstanding, which does not allow the burner to be turned off once it is turned on. Seventh, some important practical constraints are ignored, such as minimum heating limits on production units, ramp rates constraints of power generation equipment. Last, the effect of different penalty factors in the objective function on optimization results is not investigated and methods to generate the values for those penalty factors are missing.

Recent advances [15-20] have addressed at most three limitations, not all of them. For instance, Kong et al. [15] proposed an improved multi-period MILP model for optimal distribution of byproduct gases in an iron and steel plant with variable amount of byproduct gases consumed in production system. Two types of byproduct gas users in production system including singleconsuming and mixed-consuming users were considered with minimum heating value requirement for mixed-consuming users. Zhang et al. [16] presented a multi-period MILP model for optimal distribution of byproduct gases, steam, and electricity in an iron and steel plant simultaneously. Different types of steam such as high-pressure, middle-pressure, and low-pressure steam were considered to be generated from boilers, and steam turbines. The electricity is allowed to be purchased from the grid. Zhao et al. [17] proposed a very similar model of Kim et al. [14] to investigate the effect of the penalty factors in the objective function on optimization results. Junior et al. [18] improved the previous MILP model of Kim et al. [14] for the optimization of byproduct gas supply system including the minimum and maximum fuel flows within which burners in a boiler furnace may operate, and a heuristic procedure to generate appropriate weight values for penalties in the objective function. Zeng et al. [19] proposed a generalized multi-period formulation for shortterm scheduling of steam power system in an iron and steel plant with the consideration of the timeof-use power prices. Models for boilers, turbines, CHP and waste heat and energy recovery units, and several practical constraints such as ramp rate limits on turbines were introduced. Yang et al. [20] developed a multi-period model for optimal allocation of surplus gas only in gasholders and boilers in the iron and steel industry. They proposed some method to calculate the penalty weights which change with the operating condition of the equipment. Although the design fuel load of a boiler and the capacity of a gasholder were studies to obtain suitable capacities and their relationship was established to improve boiler efficiency, increase power generation, and reduce gas emissions, these aspects are beyond the scope of this paper.

In this paper, we address all of the above limitations except the last one related with the determination of penalty factors which will be addressed in our future publication. We develop a 
multi-period MILP model for optimal distribution of byproduct gases, steam and power in production units, boilers, turbines, CHP, and waste heat and energy recovery units simultaneously. The consuming rates of byproduct gases in production units are assumed to be variable. The steam is specifically classified as high-pressure, medium-pressure and low-pressure steam. New binary variables are introduced to determine electricity purchase or sale decision with each having different prices. The burner switching operations in a boiler is correctly modeled allowing turning on or off in each period with fewer binary variables. In addition, several important practical features such as fuel selection, gasholder level control, allowable flare emissions, minimum heating requirements for single and mixed consuming users, ramp rate variations of power generation units, piecewise constant generation rates of byproduct gases, and piecewise constant demand profiles of byproduct gases, steam and electricity are also incorporated into the model. The computational results demonstrate that the proposed model successfully solves an industrial example to optimality within 2 CPU second. The total operating cost is reduced by $6 \%$ using the proposed model compared to that from real operation.

\section{Problem Statement}

Figure 1 illustrates a schematic diagram of byproduct gases, steam, and electricity distribution in a typical iron and steel plant. The superstructure for such distribution is presented in Figure 2. There are total $U(u=1,2, \ldots, U)$ production units, $I(i=1,2,3, \ldots, I)$ fuel boilers, $J(j=1,2, \ldots, J)$ steam turbines, $K(k=1,2, \ldots, K)$ combined heat and power (CHP) units, and $M(m=1,2, \ldots, M)$ waste heat and energy recovery units. A CHP unit may contain several identical fuel boilers, which are denoted as $\mathbf{I}_{k} \cdot Q(q=1,2, \ldots, Q)$ types of energy sources such as byproduct gas, coal, natural gas, and fuel oil can be used in fuel boilers and some production units as fuels. While byproduct gases are generated from some production units such as coke ovens, blast furnace, and basic oxygen furnace, other energy sources such as coal, natural gas and fuel oil are purchased from outside. Byproduct gases generated from coke ovens, blast furnace, and basic oxygen furnace are called COG, BFG, and LDG, respectively, which are included in a set $\mathbf{Q}^{g}$. The production rates of byproduct gases vary at different times and are assumed to be piecewise constant. Byproduct gases are either provided for production units, boilers, and CHP units as fuels, or stored in their dedicated gasholders. The demands of byproduct gases from production units vary with times and are assumed to be piecewise constant.

Byproduct gases are fed through their dedicated and identical burners into boiler furnaces. The boiler load may vary from time to time and usually controlled by switching on/off burners. To maintain a steady feed load of a boiler, the switching operations of burners should be minimized. A penalty is imposed once the status of a burner changes. Additional penalties are imposed for simultaneously switching two or three burners. Each dedicated gasholder has its minimum and maximum capacities, a normal inventory level and safe operational region as illustrated in Figure 3. 
When a gasholder reaches its maximum capacity, excess byproduct gas has to be sent to the flare stacks, resulting in a penalty for gas emission. The inventory level in a gasholder at a time should be maintained at its normal point, which is allowed to be violated with a penalty imposed.

Total $R(r=1,2, \ldots, R)$ levels of steam are generated from fresh water in boilers, CHP units, and waste heat and energy recovery units, and consumed in production units and turbines. The demands for different levels of steam in production units may vary from time to time and are assumed to be piecewise constant. The electricity generated from turbines, CHP units, and waste heat and energy recovery units is used to provide energy for some production units such as basic oxygen furnace with known demand profiles with time, which is assumed to be piecewise constant. While excess electricity is sold to the grid with the sale price (denoted as $C_{t}^{\exp }$ ), insufficient electricity is purchased from the grid with the purchase price (denoted as $C_{t}^{i m p}$ ).

The entire planning problem of the integrated production and energy system in an iron and steel plant is defined as follows,

Given:

1. Byproduct gases, their types, suitable production units, boilers, and CHP units that are byproduct gas users, heating values, and generation rate at a time and demand profiles in production units;

2. Dedicated gasholders, their minimum and maximum capacities, normal inventory levels, high and low inventory levels for safe operational regions;

3. Fuel boilers, suitable fuels that can be fed, suitable steams that can be generated, maximum inlet flow rates of byproduct gases, thermal efficiency, minimum and maximum steam generation rates, and minimum heating values;

4. Burners, suitable byproduct gases, initial status, and feed rates at a time;

5. Steam turbines, suitable steams that can be fed, suitable steams that can be generated, suitable exhaust that can be released, minimum and maximum feed rates, thermal efficiency, minimum and maximum generation rates, and minimum and maximum power generation rates;

6. CHP units, suitable fuels that can be used, suitable steams that can be generated, minimum and maximum feed rates of byproduct gases, thermal efficiency, minimum and maximum allowable steam generation rates, minimum and maximum allowable power generation rates, and minimum heating values;

7. Waste heat and energy recovery units, minimum and maximum allowable steam generation rates, minimum and maximum allowable power generation rates, thermal efficiency, and amount of heat and energy recovered at a time;

8. Steam and electricity demand profiles with time, steam enthalpy, electricity energy content, maximum imported power from the grid, and maximum exported power to the grid; 
9. Economic data: coal and natural gas purchase cost, electricity sale price and purchase cost, penalty coefficients for byproduct gas emissions, and burner switching operations, penalty coefficients for deviations from normal inventory levels in gasholders, and violations of low and high inventory levels of the safe operational region in a gasholder, and maintenance cost for steam and power generation units;

10. Enthalpy of fresh water and exhaust;

11. Planning horizon.

Determine:

1. Optimal selection of different energy sources such as byproduct gases, coal, and natural gas in boilers at a time;

2. Optimal distribution of byproduct gases, steam and power among boilers, turbines, CHP, waste heat and energy recovery units, and production units at a time;

3. Inventory profiles of gasholders in the horizon;

4. Optimal switching operations for burners in boiler at a time. Assumptions:

1. All parameters are deterministic;

2. Byproduct gas generation rates in production units are piecewise constant;

3. Demands of byproduct gases in production units are piecewise constant;

4. Demands of steam in production units are piecewise constant;

5. Demand of electricity in production units is piecewise constant;

6. The cost of fresh water is negligible compared to other cost;

7. Issues related with unit or plant startups and shutdowns are not involved.

Our objective is to minimize total operating cost including purchase cost of energy sources such as coal and natural gas, electricity cost, equipment maintenance cost, and some penalties such as penalty for byproduct gas emissions, penalty for burner switches, and penalty for deviations from the normal inventory levels in gasholders.

\section{Mathematical Formulation}

The entire planning horizon is divided into $T$ periods $(t=1,2, \ldots, T)$ based on piecewise constant generation rates profiles of byproduct gases, and piecewise constant demand profiles of byproduct gases, steam and electricity, which is very similar to the approach used by both Li et al. [21] and Li et al. [22]. Each period starts at $H_{t-1}$ and ends at $H_{t}$ with $H_{0}=0$, as shown in Figure 4. The length of each period $t$ is denoted as $\tau_{t}$. In other words,

$$
\tau_{t}=H_{t}-H_{t-1}
$$$$
\forall t
$$

\subsection{Steam and power generation model}

The steam and power generation system in an iron and steel plant involves fuel boilers, steam 
turbines, CHP units, and waste heat and energy recovery units. Detailed mathematical modeling these units are presented below.

\section{Operational model for fuel boilers}

Industrial fuel boilers are usually used to generate steam with required pressure and temperature through transferring heat released from the combustion of a fuel or a fuel mixture to the water/steam circuit. The thermal efficiency of a boiler mainly depends on its design size and actual operating load. Empirical data (see Figure 5) have shown that the efficiency of an industrial boiler often levels off when its operating load reaches at least $50 \%$ of its design load [23]. This is also true for large boilers whose efficiency calculated using nonlinear correlations is almost constant with a maximum deviation within $1 \%$. Therefore, it is reasonable to assume constant thermal efficiency for industrial boilers when their actual operating loads exceed $50 \%$ of their design loads.

An industrial boiler can consume different types of fuels simultaneously such as byproduct gas, natural gas, coal, and fuel oil to produce different levels of steam. A typical multi-fuel boiler is shown in Figure 6. We define positive variables $F_{i q t}$ as the feed flow rate of the $q$ type of fuel to a boiler $i$ during period $t$. We define positive variables $F_{\text {irt }}$ to denote the flow rate of the $r$ level steam generated from a boiler $i$ during period $t$. The flow rate of water feed to a boiler $i$ during time period $t$ is denoted as $F_{i t}^{w}$. The constant thermal efficiency for a boiler $i$ is defined as $\eta_{i}$. The heating value of the $q$ type of fuel is defined as $H V_{q}$. The enthalpies of the $r$ level of steam and water are defined as $H_{r}^{s t m}$ and $H^{w}$, respectively. In a boiler $i$, total amount of outlet steams should be equivalent to that of its feed water during each period $t$.

$$
\sum_{r}\left(F_{i t r} \cdot \tau_{t}\right)=F_{i t}^{w} \cdot \tau_{t} \quad \forall i, t
$$

The energy balance for a boiler $i$ in each period $t$ is expressed as follows,

$$
\sum_{r=1}^{R}\left(F_{i r t} \cdot \tau_{t} \cdot H_{r}^{s t m}\right)-F_{i t}^{w} \cdot H^{w} \cdot \tau_{t}=\eta_{i} \cdot\left[\sum_{q=1}^{Q}\left(F_{i q t} \cdot \tau_{t} \cdot\right)\right] \quad \forall i \notin \mathbf{I}_{k}, t
$$

The flow rate of the $r$ level steam generated in a boiler $i$ during a period $t$ must be within some lower $\left(F_{i r}^{\min }\right)$ and upper $\left(F_{i r}^{\max }\right)$ limits,

$$
F_{i r}^{\min } \leq F_{i r t} \leq F_{i r}^{\max } \quad \forall i \notin \mathbf{I}_{k}, r, t
$$

The feed flow rate of the $q$ type of byproduct gases to a boiler $i$ during a period $t$ should not exceed some maximum limit (denoted as $F_{i q}^{\max }$ ) in order to maintain combustion during realistic operations.

$$
F_{i q t} \leq F_{i q}^{\max }
$$$$
\forall i \notin \mathbf{I}_{k}, t, q \in \mathbf{Q}^{g}
$$

The total heating value provided by byproduct gases to a boiler $i$ should exceed some required 
1 minimum heating value, which is denoted as $H V_{i}^{\min }$.

$$
\sum_{q \in \mathbf{Q}^{g}}\left(F_{i q t} \cdot \tau_{t} \cdot H V_{q}\right) \geq\left[\sum_{q \in \mathbf{Q}^{g}}\left(F_{i q t} \cdot \tau_{t}\right)\right] \cdot H V_{i}^{\min } \quad \forall i \notin \mathbf{I}_{k}, t
$$

\section{Operational model for steam turbines}

A steam turbine usually expands high-pressure steam to medium or low-pressure. The extracted mechanical energy is used to drive an electricity generator. There are three main categories of steam turbines: back pressure turbines, condensing turbines and extraction turbines [24]. While a back pressure turbine expands its inlet steam to a superheated one at a predefined pressure, a condensing turbine expands its inlet steam with high pressure into a partially condensed state. Thus, only one low-level steam is generated from such turbines through expanding a high-level steam [24]. An extraction turbine expands an inlet steam with high pressure into several intermediates with different pressures through series of stages. The steam extracted from intermediate stages is called the extraction steam, which could be used to meet industrial steam requirements. The extraction turbine can be further divided into extraction-condensing steam turbine and extraction-back pressure steam turbine. The steam from the last stage in extraction-condensing steam turbine is called the exhaust steam, which is usually condensed and used in the boiler as feed water due to its low enthalpy.

The material flow of a typical steam turbine is shown in Figure 7. We define variables $F_{j t}^{i n}$ and $F_{j t}^{o u t}$ as the inlet and outlet flow rates of steam into and from a turbine $j$ during period $t$, respectively. The inlet and outlet flow rates of the $r$ level of steam in a turbine $j$ during period $t$ are denoted as $F_{j r t}^{i n}$ and $F_{j r t}^{\text {out }}$. The flow rate of an exhaust steam from a turbine $j$ during period $t$ is represented by $F_{j t}^{e x h}$. The thermal efficiency of a turbine $j$ is defined as $\eta_{j}$.

Total amount of outlet steams in a turbine should be equivalent to that of its inlet steams during each period.

$$
F_{j t}^{i n} \cdot \tau_{t}=F_{j t}^{o u t} \cdot \tau_{t} \quad \forall j, t
$$

Total amount of inlet steams in a turbine during each period is computed as follows,

$$
\sum_{r}\left(F_{j r t}^{i n} \cdot \tau_{t}\right)=F_{j t}^{i n} \cdot \tau_{t} \quad \forall j, t
$$

Total amount of outlet steams from a turbine $j$ in period $t$ is given below,

$$
F_{j t}^{\text {out }} \cdot \tau_{t}=\sum_{r}\left(F_{j r t}^{\text {out }} \cdot \tau_{t}\right)+F_{j t}^{\text {exh }} \cdot \tau_{t} \quad \forall j, t
$$

Note that $F_{j t}^{e x h}=0$ for back pressure turbines since no exhaust steam to the condenser is generated and, and $F_{j r t}^{\text {out }}=0$ for condensing turbines since these turbines receive steam and exhaust it to a condenser.

We define $P_{j t}$ as the power generation rate from a turbine $j$ during time period $t$. The power generated from a turbine $j$ in each period $t$ is calculated using the following constraints. 


$$
P_{j, t} \cdot \tau_{t} \cdot H C^{P}=\eta_{j} \cdot\left[\sum_{r=1}^{R}\left(F_{j r t}^{i n} \cdot \tau_{t} \cdot H_{r}^{s t m}\right)-\sum_{r=1}^{R}\left(F_{j r t}^{o u t} \cdot \tau_{t} \cdot H_{r}^{s t m}\right)-F_{j t}^{e x h} \cdot \tau_{t} \cdot H_{j}^{e x h}\right] \quad \forall j, t
$$

where, $H C^{P}$ represents the energy content of electricity.

The feed rate of the $r$ level of steam to a turbine during period $t$ must meet its lower $\left(F_{j r}^{i n, \min }\right)$ and upper $\left(F_{j r}^{i n, \max }\right)$ limits.

$$
F_{j r}^{i n, \min } \leq F_{j r t}^{i n} \leq F_{j r}^{i n, \max } \quad \forall j, r, t
$$

Similarly, the output flow rate of the $r$ level of steam from a turbine in period $t$ must satisfy its lower $\left(F_{j r}^{\text {out,min }}\right)$ and upper $\left(F_{j r}^{\text {out,max }}\right)$ limits.

$$
F_{j r}^{\text {out,min }} \leq F_{j r t}^{\text {out }} \leq F_{j r}^{\text {out,max }} \quad \forall j, r, t
$$

The electricity generation rate from a turbine $j$ during each period should satisfy some lower ( $\left.F_{j}^{\min }\right)$ and upper $\left(F_{j}^{\max }\right)$ limits.

$$
P_{j}^{\min } \leq P_{j t} \leq P_{j}^{\max }
$$$$
\forall j, t
$$

\section{CHP operational model}

A typical CHP unit may include fuel boilers, heat recovery boilers, steam turbines, gas turbines, and other heat recovery and steam generation units. While all inputs for a CHP unit are fresh water and different types of energy sources such as byproduct gas, coal and natural gas, all output from a CHP unit include steam and power. In recent years, many studies have been conducted on modelling of the CHP plant using data-drive approach [25] or first-principle approach [26]. Although these models can track different operational modes of each component in a CHP unit, they are too complicated to be used for plant planning. For the sake of simplification, a constant efficiency is assumed for a typical CHP unit (see Figure 8) during the entire planning horizon. We define $P_{k t}$ to represent the electric power generation rate from a CHP unit $k$ during period $t$, and $F_{k r t}$ to denote the flow rate of the $r$ level of steam generated from a CHP unit $k$ in period $t$. The energy balance for a CHP unit is represented using eq. 14 in the following:

$$
P_{k t} \cdot \tau_{t} \cdot H C^{P}+\sum_{r=1}^{R}\left(F_{k r t} \cdot \tau_{t} \cdot H_{r}^{s t m}-F_{k r t} \cdot \tau_{t} \cdot H^{w}\right)=\eta_{k} \cdot\left[\sum_{i \in \mathbf{I}_{k}} \sum_{q=1}^{Q}\left(F_{i q t} \cdot \tau_{t} \cdot H V_{q}\right)\right] \quad \forall k, t
$$

where, $F_{\text {iqt }}$ is the feed rate of the $q$ type of byproduct gases to a fuel boiler $i$ in a CHP unit $k$.

The total feed of the $q$ type of byproduct gases to a CHP unit $k$ in each period should be within some lower and upper limits:

$$
F_{k q}^{\min } \cdot \tau_{t} \leq\left(\sum_{i \in \mathbf{I}_{k}} F_{i q t}\right) \cdot \tau_{t} \leq F_{k q}^{\max } \cdot \tau_{t} \quad \forall k, t, q \in \mathbf{Q}^{g}
$$

where, $F_{k q}^{\min }$ and $F_{k q}^{\max }$ are the minimum and maximum allowable feed rates of the $q$ type of byproduct 
gases to a CHP unit $k$, respectively.

Similarly, the electricity and steam generation rates from a CHP unit $k$ during each period should also meet their lower and upper limits.

$$
\begin{array}{ll}
F_{k r}^{\min } \leq F_{k r t} \leq F_{k r}^{\max } & \forall k, r, t \\
P_{k}^{\min } \leq P_{k t} \leq P_{k}^{\max } & \forall k, t
\end{array}
$$

where, $F_{k r}^{\min }$ and $F_{k q}^{\max }$ are minimum and maximum allowable generation rates of the $r$ level of steam in a CHP unit $k$, respectively. $P_{k}^{\min }$ and $P_{k}^{\max }$ are minimum and maximum allowable generation rates of power in a CHP unit $k$, respectively.

The heating value for a CHP unit provided by byproduct gases should exceed some minimum requirement $\left(H V_{k}^{\min }\right)$.

$$
\sum_{i \in \mathbf{I}_{k}} \sum_{q \in \mathbf{Q}^{g}}\left(F_{i q t} \cdot \tau_{t} \cdot H V_{q}\right) \geq H V_{k}^{\min } \cdot\left[\sum_{i \in \mathbf{I}_{k}} \sum_{q \in \mathbf{Q}^{g}}\left(F_{i q t} \cdot \tau_{t}\right)\right] \quad \forall k, t
$$

\section{Operational model for waste heat and energy recovery units}

Waste heat and energy recovery equipment such as coke dry quenching (CDQ) units and top pressure recovery turbines are widely used to recover waste heat and energy from production units and generate steam and power in an iron and steel plant. A typical waste heat and energy recovery unit is illustrated in Figure 9. We define positive variables $P_{m t}$ to represent electric power generation rate from a waste heat and energy recovery unit in period $t$, and positive variables $F_{m r t}$ as the generation rate of the $r$ level of steam from a waste heat and energy recovery unit in period $t$. We also define parameters $E_{m t}^{\text {in }}$ to denote the total amount of waste heat and energy recovered in a waste heat and energy recovery unit in period $t$. The thermal efficiency of a waste heat and energy recovery unit is denoted as $\eta_{m}$. The energy balance in a waste heat and energy recovery unit is computed as follows,

$$
P_{m t} \cdot \tau_{t} \cdot H C^{P}+\sum_{r=1}^{R}\left(F_{m r t} \cdot \tau_{t} \cdot H_{r}^{s t m}-F_{m r t} \cdot \tau_{t} \cdot H^{w}\right)=\eta_{m} \cdot E_{m t}^{i n} \quad \forall m, t
$$

The electricity and steam generation rates from waste heat and energy recovery equipment should satisfy some lower and upper limits, which are expressed as follows,

$$
P_{m}^{\min } \leq P_{m t} \leq P_{m}^{\max } \quad \forall m, t
$$

where, $P_{m}^{\min }$ and $P_{m}^{\max }$ are the minimum and maximum allowable power generation rates in a waste heat and energy recovery unit $m$ during period $t$.

$$
F_{m r}^{\min } \leq F_{m r t} \leq F_{m r}^{\max } \quad \forall m, r, t
$$

where, $F_{m r}^{\min }$ and $F_{m r}^{\max }$ are the minimum and maximum allowable generation rates of the $r$ level of steam in a waste heat and energy recovery unit $m$ during period $t$. 
3.2 Byproduct gas, steam and power balances

The total electricity generated from power generation units (i.e., steam turbines, CHP, and waste heat and energy recovery equipment) must meet electricity demand from production units in each time period, which is denoted as $P_{t}^{d e m}$. The electricity purchased from the grid during each period is defined as $P_{t}^{i m p}$, and the electricity sold to the grid in each period is defined as $P_{t}^{\exp }$. The overall electricity balance is given below,

$$
\sum_{j=1}^{J}\left(P_{j t} \cdot \tau_{t}\right)+\sum_{k=1}^{K}\left(P_{k t} \cdot \tau_{t}\right)+\sum_{m=1}^{M}\left(P_{m t} \cdot \tau_{t}\right)+P_{t}^{i m p}=P_{t}^{d e m}+P_{t}^{\text {exp }}
$$$$
\forall t
$$

As mentioned before, electricity purchase and sale activities are not allowed to take place at the same time. To enforce this, we define binary variables $y_{P, t}^{i m p}$ and $0-1$ continuous variables $y_{P, t}^{\exp }$ as follows,

$$
y_{P, t}^{i m p}= \begin{cases}1 & \text { if electricty } P \text { is purchased from the grid duirng period } t \\ 0 & \text { otherwise }\end{cases}
$$$$
y_{P, t}^{\exp }= \begin{cases}1 & \text { if electricty } P \text { is sold to the grid duirng period } t \\ 0 & \text { otherwise }\end{cases}
$$

The purchase and sale activities are not allowed to take place simultaneously at any time, which is enforced below,

$$
y_{P, t}^{i m p}+y_{P, t}^{\mathrm{exp}}=1
$$$$
\forall t
$$

The amount of electricity power that is purchased from or sold to the power grid should satisfy some upper limit which is imposed in an energy exchange contract with the grid,

$$
\begin{array}{ll}
P_{t}^{\text {imp }} \leq P_{t}^{\text {imp,max }} \cdot y_{P, t}^{\text {imp }} & \forall t \\
P_{t}^{\text {exp }} \leq P_{t}^{\text {exp,max }} \cdot y_{P, t}^{\text {exp }} & \forall t
\end{array}
$$

where, $P_{t}^{i m p, \max }$ and $P_{t}^{\text {exp, max }}$ represent maximum imported power and maximum exported power during period $t$, respectively.

The steam generated from boilers, CHP units, and waste heat and energy recovery units is provided to production units and turbines. We define a parameter $D_{r t}^{d e m}$ to denote the demand of the $r$ level of steam required in production units during period $t$. The $r$ level of steam balance in each period can be represented by:

$$
\sum_{i \notin \mathbf{I}_{k}}\left(F_{i r t} \cdot \tau_{t}\right)+\sum_{k=1}^{K}\left(F_{k r t} \cdot \tau_{t}\right)+\sum_{m=1}^{M}\left(F_{m r t} \cdot \tau_{t}\right)+\left[\sum_{j=1}^{J}\left(F_{j r t}^{o u t} \cdot \tau_{t}\right)-\sum_{j=1}^{J}\left(F_{j r t}^{i n} \cdot \tau_{t}\right)\right]=D_{r t}^{\text {dem }} \quad \forall r, t
$$

We define $I n v_{q t}$ to denote the inventory level of the $q$ type of byproduct gas in the gasholder at the end of period $t, F_{q t}^{G e n}$ as the generation rate of the $q$ type of byproduct gas in period $t$, and $F_{u q t}$ as 
the consumption rate of the $q$ type of byproduct gas in a production unit $u$ during period $t$. The amount of byproduct gas emissions during period $t$ is denoted as $Q_{q t}^{\text {emission }}$. The inventory level of a gasholder at the end of period $t$ is calculated as follows,

$$
\operatorname{Inv} v_{q t}=\operatorname{In} v_{q(t-1)}+F_{q t}^{G e n} \cdot \tau_{t}-\sum_{u=1}^{U}\left(F_{u q t} \cdot \tau_{t}\right)-\sum_{i=1}^{I}\left(F_{i q t} \cdot \tau_{t}\right)-Q_{q t}^{\text {emission }} \quad \forall q \in \mathbf{Q}^{g}, t
$$

The inventory level of a gasholder during each period must satisfy its minimum $(\operatorname{Inv} \underset{q}{\min })$ and $\operatorname{maximum}(\operatorname{Inv} \underset{q}{\max })$ inventory levels.

$$
\operatorname{Inv} v_{q}^{\min } \leq \operatorname{In} v_{q t} \leq \operatorname{In} v_{q}^{\max } \quad \forall q \in \mathbf{Q}^{g}, t
$$

\subsection{Gasholder operational model}

Each dedicated gasholder has its own desired operational requirements. There is a safe operational region with high and low inventory levels as highlighted with yellow background color in Figure 3. If the gasholder is operated within the safe operational zone, it is easy to accommodate excess or shortage of byproduct gas. The high and low inventory levels in a safe operational zone are denoted as $\operatorname{In} v_{q}^{H}$ and $\operatorname{In} v_{q}^{L}$, respectively. Once the gasholder level exceeds $\operatorname{In} v_{q}^{H}$ or is lower than $\operatorname{In} v_{q}^{L}$, a penalty is imposed. To achieve this, two positive slack variables $\operatorname{SInv} v_{q t}^{L}$ and $\operatorname{SIn} v_{q t}^{H}$ are defined as the violation of $\operatorname{In} v_{q}^{H}$ and $\operatorname{In} v_{q}^{L}$.

$$
\operatorname{In} v_{q}^{L}-\operatorname{SIn} v_{q t}^{L} \leq \operatorname{In} v_{q t} \leq \operatorname{In} v_{q}^{H}+\operatorname{SIn} v_{q t}^{H} \quad \forall q \in \mathbf{Q}^{g}, t
$$

In addition, a gasholder is usually operated at its normal inventory level, which is denoted as $\operatorname{Inv} v_{q}^{N}$. When the inventory level deviates from its normal inventory level, a penalty is enforced. We introduce two positive slack variables $\operatorname{SIn} v_{q t}^{d^{+}}$and $\operatorname{SIn} v_{q t}^{d^{-}}$to represent the deviation of a gasholder level from its normal point at any time.

$$
\operatorname{In} v_{q t}-\operatorname{In} v_{q}^{N}=\operatorname{SIn} v_{q t}^{d^{+}}-\operatorname{SIn} v_{q t}^{d^{-}} \quad \forall q \in \mathbf{Q}^{g}, t
$$

\subsection{Burner operational constraints}

An industrial fuel boiler in an iron and steel plant usually has installed several identical burners, which are used to introduce different types of byproduct gases. The byproduct gas load is controlled by switching on and off burners. However, keeping switching on and off burners could result in unstable operation, which may lead to backfire or incomplete combustion. Therefore, the number of switching operations should be minimized. We define $N_{\text {iqt }}$ to denote the number of burners whose status is on for the $q$ type of byproduct gas in time period $t$. The number of burners whose status is changed in period $t$ is represented using variables $\Delta N_{i q t}$. In real operations, at most three burners can change their status in each period.

Total amount of the $q$ type of byproduct gases into a boiler $i$ in each time period is calculated 
using the following constraints,

$$
F_{i q t} \cdot \tau_{t}=F_{i q} \cdot N_{i q t} \cdot \tau_{t} \quad \forall i, q \in \mathbf{Q}^{g}, t
$$

where, $F_{i q}$ is a parameter representing the inlet flow rate of a burner for the $q$ type of byproduct gas in a boiler $i$.

The number of burners whose status is changed in period $t\left(\Delta N_{i q t}\right)$ is computed below,

$$
\begin{array}{ll}
\Delta N_{i q t} \geq N_{i q t}-N 0_{i q} & \forall i, q \in \mathbf{Q}^{g}, t=1 \\
\Delta N_{i q t} \geq N 0_{i q}-N_{i q t} & \forall i, q \in \mathbf{Q}^{g}, t=1 \\
\Delta N_{i q t} \geq N_{i q t}-N_{i q(t-1)} & \forall i, q \in \mathbf{Q}^{g}, t>1 \\
\Delta N_{i q t} \geq N_{i q(t-1)}-N_{i q t} & \forall i, q \in \mathbf{Q}^{g}, t>1
\end{array}
$$

where, $N 0_{i q}$ denotes the initial number of burners whose status is on is known a prior.

In each period, the operator may switch zero, one, two or three burners for each type of byproduct gases. To model this operation, we define binary variables $i b n 1_{\text {iqt }}^{+}, i b n 2_{\text {iqt }}^{+}$, and $i b n 3_{\text {iqt }}^{+}$, and $0-1$ continuous variables $i b n 0_{i q t}$ below,

$i b n 0_{i q t}= \begin{cases}1 & \text { if no burner for } q \text { type of byproduct gases in a boiler } i \text { changes status in } t \\ 0 & \text { otherwise }\end{cases}$ $i b n 1_{i q t}^{+}= \begin{cases}1 & \text { if only one burner for } q \text { type of byproduct gases in a boiler } i \text { changes its status in } t \\ 0 & \text { otherwise }\end{cases}$ $i b n 2_{i q t}^{+}= \begin{cases}1 & \text { if two burners for } q \text { type of byproduct gases in a boiler } i \text { change their status in } t \\ 0 & \text { otherwise }\end{cases}$ $i b n 3_{i q t}^{+}= \begin{cases}1 & \text { if three burners for } q \text { type of byproduct gases in a boiler } i \text { change their status in } t \\ 0 & \text { otherwise }\end{cases}$ The number of burners whose status has been changed in period $t$ can be represented by,

$$
\Delta N_{i q t}=i b n 1_{i q t}^{+}+i b n 2_{\text {iqt }}^{+}+i b n 3_{\text {iqt }}^{+} \quad \forall i, q \in \mathbf{Q}^{g}, t
$$

The relationship of these binary variables can be expressed as follows,

$$
\begin{array}{ll}
i b n 1_{i q t}^{+} \geq i b n 2_{i q t}^{+} \geq i b n 3_{i q t}^{+} & \forall i, q \in \mathbf{Q}^{g}, t \\
i b n 0_{i q t}+i b n 1_{i q t}^{+}=1 & \forall i, q \in \mathbf{Q}^{g}, t \\
i b n 0_{i q t}+i b n 2_{i q t}^{+} \leq 1 & \forall i, q \in \mathbf{Q}^{g}, t \\
i b n 0_{i q t}+i b n 3_{i q t}^{+} \leq 1 & \forall i, q \in \mathbf{Q}^{g}, t
\end{array}
$$

\subsection{Ramp rate on power generation}

The ramp rate defined as the rate at which a turbine can increase or decrease its output, must be in an acceptable range to avoid over pressure on turbines which could result in their lifetime decrease. This can be ensured using eqs. 37-39. 


$$
\begin{array}{ll}
-D R_{j} \leq \frac{P_{j t}}{\tau_{t}}-\frac{P_{j(t-1)}}{\tau_{t-1}} \leq U R_{j} & \forall j, t \\
-D R_{k} \leq \frac{P_{k, t}}{\tau_{t}}-\frac{P_{k(t-1)}}{\tau_{t-1}} \leq U R_{k} & \forall k, t \\
-D R_{m} \leq \frac{P_{m, t}}{\tau_{t-1}}-\frac{P_{m(t-1)}}{\tau_{t-1}} \leq U R_{m} & \forall m, t
\end{array}
$$

where, $U R_{j}$ and $D R_{j}$ are the maximum ramp up and down rates of turbine $j$, respectively; $U R_{k}$ and $D R_{k}$ are the maximum ramp up and down rates of CHP unit $k$, respectively; $U R_{m}$ and $D R_{m}$ are the maximum ramp up and down rates of waste heat recovery equipment $m$, respectively.

\subsection{Byproduct gas constraints for production units}

While some byproduct gas users consume only one type of byproduct gases, some users require a mixture of byproduct gases. The feed rate of the $q$ type of byproduct gases must meet some lower ( $\left.F_{u q}^{\min }\right)$ and upper $\left(F_{u q}^{\max }\right)$ limits.

$$
F_{u q}^{\min } \leq F_{u q t} \leq F_{u q}^{\max } \quad \forall u, q \in \mathbf{Q}^{g}, t
$$

For single consuming users, their feed amount in a time period should meet their demands, which is denoted as $D_{u q t}^{\text {dem }}$.

$$
F_{u q t} \cdot \tau_{t} \geq D_{u q t}^{d e m} \quad \forall u, q \in \mathbf{Q}^{g}, t
$$

For mixed consuming users, their minimum heating value and energy demand should be satisfied.

$$
\begin{array}{ll}
\sum_{q \in \mathbf{Q}^{\mathbf{g}}}\left(F_{u q t} \cdot \tau_{t} \cdot H V_{q}\right) \geq H V_{u}^{\min } \cdot \sum_{q \in \mathbf{Q}^{\mathbf{g}}}\left(F_{u q t} \cdot \tau_{t}\right) & \forall u, t, H V_{u}^{\min }>0 \\
\sum_{q \in \mathbf{Q}^{g}}\left(F_{u q t} \cdot \tau_{t} \cdot H V_{q}\right) \geq E_{u t}^{D e m} & \forall u, t, E_{u t}^{D e m}>0
\end{array}
$$

where, $H V_{u}^{\min }$ and $E_{u t}^{D e m}$ are the minimum heating value and energy demand for a production unit $u$, respectively.

\subsection{Objective function}

Our objective is to minimize total operational cost (denoted as $T C$ ), which consists of purchase cost of coal and natural gas, electricity purchase cost, some penalty cost, and maintenance cost. The total operational cost is calculated as follows,

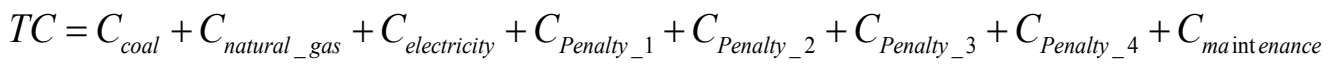

$$
\begin{aligned}
& C_{\text {coal }}=\sum_{t=1}^{T} \sum_{i=1}^{I} \sum_{q={ }^{\prime} \text { coal' }}\left(C_{q} \cdot F_{i q t} \cdot \tau_{t}\right)+\sum_{t=1}^{T} \sum_{k=1}^{K} \sum_{q=' \text { coal' }}\left(C_{q} \cdot F_{k q t} \cdot \tau_{t}\right)
\end{aligned}
$$


$1 \quad C_{\text {natural_gas }}=\sum_{t=1}^{T} \sum_{i=1}^{I} \sum_{q==^{\prime \prime n a t u r a l} \_ \text {gas' }}\left(C_{q} \cdot F_{\text {iqt }} \cdot \tau_{t}\right)+\sum_{t=1}^{T} \sum_{k=1}^{K} \sum_{q=\text { 'natural_gas' }}\left(C_{q} \cdot F_{k q t} \cdot \tau_{t}\right)$

$2 \quad C_{\text {electricity }}=\sum_{t=1}^{T}\left(C_{t}^{\text {exp }} \times P_{t}^{\text {exp }} \times \tau_{t}\right)-\sum_{t=1}^{T}\left(C_{t}^{i m p} \times P_{t}^{\text {imp }} \times \tau_{t}\right)$

$3 \quad C_{\text {Penalty } \_1}=\sum_{t=1}^{T} \sum_{q \in \mathbf{Q}^{\mathrm{g}}}\left[\left(W_{q}^{\text {emission }} \cdot Q_{q t}^{\text {emission }}\right)\right]$

$4 \quad C_{\text {Penalty } 2}=\sum_{t=1}^{T} \sum_{q \in \mathbf{Q}^{\mathrm{g}}}\left[\left(\mathrm{W}_{q}^{L} \cdot \operatorname{SIn} v_{q t}^{L}+\mathrm{W}_{q}^{H} \cdot \operatorname{SIn} v_{q t}^{H}+\mathrm{W}_{q}^{d^{-}} \cdot \operatorname{SIn} v_{q t}^{d^{-}}+\mathrm{W}_{q}^{d^{+}} \cdot \operatorname{SIn} v_{q t}^{d^{+}}\right)\right]$

$5 \quad C_{P_{\text {enally_3 }}}=\sum_{t=1}^{T} \sum_{i=1}^{I} \sum_{q \in \mathbf{Q}^{\mathrm{g}}}\left[W_{q}^{S W} \times\left(i b n 1_{i q t}^{+}+i b n 2_{\text {iqt }}^{+}+i b n 3_{i q t}^{+}\right)\right]$

$C_{\text {Penalty_4 }}=\sum_{t=1}^{T} \sum_{i=1}^{I} \sum_{q \in \mathbf{Q}^{\mathrm{g}}}\left[W_{q}^{2 S} \times i b n 2_{i q t}^{+}+W_{q}^{3 S} \times i b n 3_{i q t}^{+}\right]$

$$
\begin{aligned}
C_{\text {maintenance }} & =\sum_{t=1}^{T} \sum_{i=1}^{I}\left(C_{i}^{M} \times F_{i t} \times \tau_{t}\right) \\
& +\sum_{t=1}^{T} \sum_{j=1}^{J}\left(C_{j}^{P M} \times P_{j t} \times \tau_{t}\right)+\sum_{t=1}^{T} \sum_{k=1}^{K}\left(C_{k}^{P M} \times P_{k t} \times \tau\right)+\sum_{t=1}^{T} \sum_{m=1}^{M}\left(C_{m}^{P M} \times P_{m t} \times \tau_{t}\right)
\end{aligned}
$$

8 where, $C_{\text {coal }}$ is the purchase cost of coal, $C_{\text {natural gas }}$ represents the purchase cost of natural gas, $C_{\text {electricity }}$ is the cost of electricity purchased from the grid. The electricity sale revenue sold to the grid is included into the cost. $C_{\text {penalty_ }}$ represents the penalty cost for the emissions of byproduct gases. $C_{\text {penalty } 2}$ represents the penalty cost for the violation of high and lower inventory levels of gasholders and their normal operation points. $C_{\text {penalty }} 3$ is the penalty cost for burner switches in fuel boilers. $C_{\text {penalty } 4}$ stands for additional penalty cost for simultaneous switches of two and three burners in fuel boilers. $C_{\text {maintenance }}$ is the maintenance cost for boilers and turbines including those in CHP and waste heat and energy recovery units. Note that the cost for fresh water is not considered in the objective function since it is much smaller compared to the cost in eq. 44 .

3.8 Lower and upper bounds

$$
0 \leq i b n 0_{i q t} \leq 1 \quad \forall i, q \in \mathbf{Q}^{g}, t
$$

We complete our mixed-integer linear programming model (MILP) denoted as M, which comprises eqs. 2-57. Binary variables are used to model switching operations of burners in fuel 
boilers, and decisions on electricity sale and purchase with each having different prices.

\section{Case Study}

We use our proposed model $\mathbf{M}$ to solve an industrial example from an iron and steel plant in China. This industrial plant consists of 4 coke ovens, 2 blast furnaces, and 5 basic oxygen furnaces. The energy system is made up of 4 boilers (B1-B4), 2 steam turbines (TB1-TB2), 2 CHP units (CHP1CHP2), and 2 CDQ units (CDQ1-CDQ2), as shown in Figure 10. TB1 and TB2 are extraction-back pressure steam turbines. There are three levels of steam that could be generated from the boilers, which are high-pressure steam S1 with a pressure of 3.5 MPa, medium-pressure steam S2 with a pressure of 1.0 MPa, and low-pressure steam S3 with a pressure of $0.4 \mathrm{MPa}$. Three types of byproduct gases are generated from the coke oven, blast furnace and basic oxygen furnace, which are COG, BFG and LDG, respectively. These byproduct gases are mainly consumed in the processes units, and the surplus can be either stored in the gas holders or used as fuels for boilers and CHP units to generate steam or electricity. It should be noted that LDG is not allowed to be used in the boilers and CHP units. While most production units such as coke ovens, pelletizing plants, and hot stoves consume single type of byproduct gases, hot strip mills use a mixed byproduct gases. The distribution of byproduct gases in production units is illustrated in Figure 11. Coal and natural gas purchased from outside can be used in the boilers and CHP units. The planning horizon is about $6 \mathrm{hr}$. All data are given in Tables 1-9.

The horizon is divided into 6 identical time periods based on demand profiles of byproduct gases, steam and electricity in production units, and generation rate profiles of byproduct gases from production units, as illustrated in Figure 4. This industrial example is solved using CPLEX 12.6.1.0/GAMS 24.4.2 on a Dell Insprion15 5000 of Intel Core i7-4510U CPU 2.0 GHz with 8GB RAM memory running Windows 7 .

\section{Computational Results and Discussions}

The model M contains 438 binary variables, 918 continuous variables, and 2,293 constraints. The optimal solution of $¥ 1,210,391$ is obtained within 2 CPU seconds. Table 10 lists comparative results from the proposed model and the actual operation. From Table 10, it can be observed that natural gas is not purchased from outside although it is allowed because of its relatively higher unit price. No byproduct gases are released into the atmosphere, achieving highly efficient utilization in the plant. The inventory levels in gasholders are maintained near their normal operating points because the penalties for violations of safe operational zone are zero. Some electricity is required to be purchased from the grid, indicating the electricity generated from turbines, CHP units, and CDQ units are insufficient for production units. The penalty for burner switches during the horizon is about $¥$ 30,900 . Table 11 summaries the number of burners whose status is on in a boiler during each period. All burner switches in a boiler are successfully controlled within the maximum allowable switches. 
The optimal distribution of byproduct gases in production units, boilers and CHP units is illustrated in Figures 12-13. From Figure 12, it can be seen that each byproduct gas user requires different amount of byproduct gases in each time period. For instance, cold rolling mills consume 30 $\mathrm{km}^{3}$ of $\mathrm{COG}$ in the first period, whilst they consume $32 \mathrm{~km}^{3}$ of COG in the second period. It can also be observed that COG is mainly consumed by $1 \#$ and $2 \#$ coke ovens, and cold rolling mills, whereas BFG is mainly consumed by hot stoves and 3\#-4\# coke ovens. From Figure 13, while COG are mainly provided for CHP units, BFG are mainly used in boilers 3-4 and CHP units. This is because the maximum allowable loads of COG in boilers 1-4 are much smaller compared to those in CHP, and the maximum allowable loads of BFG in boilers 1-2 are much smaller compared to those in boiler 34. It also can be found that the inlet flow rates of byproduct gases to each boiler remain the same in most periods, indicating frequent changes of boiler load are avoided through imposing penalty for burner switching operations. The inventory profiles of gasholders are given in Figure 14. It can be observed that the inventory level of a dedicated gasholder at any time is maintained very well around its normal level. For instance, the inventory level of BFG at any time is maintained at $180 \mathrm{~km}^{3}$, which is equivalent to its normal inventory level. Besides byproduct gases, CHP units also consume coal. The optimal distribution of coal in CHP1 and CHP2 is illustrated in Figure 15. It can be observed that CHP2 requires more coal than CHP1, which is used to generate more steam S2.

The optimal steam and electricity generation in turbines, CHP, and CDQ units is demonstrated in Figures 16-17. The optimal distribution of HP S1 in production units and turbines is illustrated in Figure 18. From Figure 16, it can be observed that S1 is generated from B1-B4. Although S1 is also generated from the boilers in CHP1, CHP2, CDQ1, and CDQ2, it is completely consumed in CHP1, $\mathrm{CHP} 2, \mathrm{CDQ} 1$, and CDQ2 for $\mathrm{S} 2, \mathrm{~S}$, and electricity generation. In other words, there is no output $\mathrm{S} 1$ from CHP1, CHP2, CDQ1, and CDQ2. While S2 is extracted from TB1, TB2, CHP1, CHP2, and CDQ2, $\mathrm{S} 3$ is extracted from TB1, TB2, and CHP2. No S2 and S3 are extracted from CDQ1. This is because all S1 generated from CDQ1 is used for electricity generation. Only S2 is extracted from CHP1. It is interesting to be observed that TB1 generates more S2 than TB2, whilst TB2 generates more S3 than TB1. From Figure 17, it can be seen that TB2 generates more electricity than TB1. This is because more S1 is fed into TB2 (see Figure 18) and less S2 is extracted compared to TB1 (see Figure 16), resulting in more steam enthalpy used for electricity generation. It is also interesting to be observed that although CHP2 generates the same amount of electricity as CHP1, CHP2 generates more S2 than CHP1 because CHP2 consumes more coal than CHP1 which is used for S2 generation. Similar conclusions can be made for CDQ1 and CDQ2 since CDQ2 recovers more energy than CDQ1 (see Table 7). The imported power from the grid is very low indicating that the electricity demand is mainly satisfied by those power generation units in the plant since the electricity purchase cost is much higher than its self-generation cost. 
We compare our results with those from the actual operation, which is presented in Table 10. The total cost from the proposed model $\mathbf{M}$ is about $¥ 1,210,391$ which is reduced by $6 \%$ compared to that of $¥ 1,291,562$ from the actual operation. Note that the cost of each item for the actual operation in Table 10 is calculated based on the actual operational data, which are presented in Tables 12-13. From Table 10, it can be observed that zero byproduct gas emission is achieved, gasholder levels are controlled in their safe operational zone at any time, and natural gas is not required to be purchased from the proposed model and the actual operation. The significant improvement from the proposed model mainly arises from the reduction of the purchase cost of electricity and coal, the penalty cost for gasholder level deviation from the normal level and the penalty cost for burner switching operations. These reductions mainly come from the simultaneous optimization of byproduct gases, steam and power generation and distribution, resulting in optimal distribution of byproduct gases in some production units, gasholders, boilers, and CHP units. This optimal distribution significantly reduces the required amount of coal from purchase and the variability in gasholder level, resulting in smaller penalty cost for the deviation of gasholder levels from normal levels at any time. The stability of gasholder levels reduces frequent changes of a boiler load, leading to less frequency of burner switches from time to time and hence reducing the penalty cost for burner switching. The introduction of CHP and waste heat and energy recovery units can generate more electricity, significantly reducing the purchase cost of electricity from the national grid. The equipment maintenance cost is slightly increased because the CHP units generate more power.

\section{Conclusions}

In this paper, we successfully developed a novel multi-period MILP model for simultaneous optimization of byproduct gas, steam and power generation and distribution in an iron and steel plant, which involved many production units, boilers, steam turbines, CHP units, and waste heat and energy recovery units. Different types of byproduct gases were allowed to be mixed to meet heating and energy requirements of production units. Integer variables were introduced to determine electricity purchase or sale decision with each having different price. The burner switching was correctly modeled with fewer integer variables allowing turning on and off at any time. Several important practical features such as fuel selection, variable consuming rates of byproduct gases, gasholder level control, ramp rate variation, piecewise constant generation rates of byproduct gases, and piecewise constant demand profiles of byproduct gases, steam and electricity were also incorporated. The computational results demonstrate that the optimal operating cost is obtained within 2 CPU seconds for an industrial example using the proposed model, which is reduced by $6 \%$ compared to that from actual operation.

\section{Acknowledgement}


1 Yujiao Zeng would like to acknowledge financial supports for this work from the National Natural

2 Science Foundation of China (21561122001) and Major Science and Technology Program for Water

3 Pollution Control and Treatment (2015ZX07202013-003). Jie Li is thankful from the National

4 Natural Science Foundation of China (21206174). 


\section{Nomenclature}

\section{Indices}

$u \quad$ Production unit index

$i \quad$ Boiler index

j Turbine index

$k \quad$ CHP unit index

$m \quad$ waste heat and energy recovery unit index

$q \quad$ Energy source index

$r \quad$ Steam level index

$t \quad$ Period index

Sets

$U \quad$ Production units

I $\quad$ Boilers

$J \quad$ Turbines

$K \quad$ CHP units

$M \quad$ Waste heat and energy recovery units

$Q \quad$ Energy sources

$\mathbf{Q}^{g} \quad$ Byproduct gases

$R \quad$ Steam levels

$T \quad$ Periods

\section{Parameters}

$H_{t-1} \quad$ Start time of period $t$

$H_{t} \quad$ End time of period $t$

$H_{0} \quad$ Start time of the planning horizon

$\tau_{t} \quad$ Time length of period $t$

$\eta_{i} \quad$ Thermal efficiency of boiler $i$

$H V_{q} \quad$ Heating value of the $q$ type of fuel

$H_{r}^{s t m} \quad$ Enthalpy of the $r$ level of steam

$H^{w} \quad$ Enthalpy of boiler feed water

$F_{i r}^{\min } \quad$ Minimum flow rate of the $r$ level steam generated from boiler $i$

$F_{i r}^{\max } \quad$ Maximum flow rate of the $r$ level steam generated from boiler $i$

$F_{i q}^{\max } \quad$ Maximum flow rate of the $q$ type of fuel fed into boiler $i$

$H V_{i}^{\text {min }} \quad$ Minimum heating value required in boiler $i$ 
$\eta_{j} \quad$ Thermal efficiency of turbine $j$

$H_{j}^{e x h} \quad$ Enthalpy of exhaust steam generated from turbine $j$

$H C^{P} \quad$ Energy content of electricity

$F_{j r}^{i n, m i n} \quad$ Minimum flow rate of the $r$ level steam into turbine $j$

$F_{j r}^{i n, \max } \quad$ Maximum flow rate of the $r$ level steam into turbine $j$

$F_{j r}^{o u t \text { min }} \quad$ Minimum flow rate of the $r$ level steam generated from turbine $j$

$F_{j r}^{o u t \text { max }} \quad$ Maximum flow rate of the $r$ level steam generated from turbine $j$

$P_{j}^{\min } \quad$ Minimum electricity generation rate from turbine $j$

$P_{j}^{\max } \quad$ Maximum electricity generation rate from turbine $j$

$D R_{j} \quad$ Maximum ramp down rate of turbine $j$

$U R_{j} \quad$ Maximum ramp up rate of turbine $j$

$\eta_{k} \quad$ Thermal efficiency of CHP unit $k$

$F_{k q}^{\min } \quad$ Minimum flow rate of the $q$ type of fuel fed into CHP unit $k$

$F_{k q}^{\max } \quad$ Maximum flow rate of the $q$ type of fuel fed into CHP unit $k$

$F_{k r}^{\min } \quad$ Minimum allowable generation rate of the $r$ level of steam from CHP unit $k$

$F_{k r}^{\max } \quad$ Maximum allowable generation rate of the $r$ level of steam from CHP unit $k$

$P_{k}^{m i n} \quad$ Minimum allowable electricity generation rate from $\mathrm{CHP}$ unit $k$

$P_{k}^{\max } \quad$ Maximum allowable electricity generation rate from $\mathrm{CHP}$ unit $k$

$H V_{k}^{\text {min }} \quad$ Minimum heating value required in CHP unit $k$

$D R_{k} \quad$ Maximum ramp down rate of CHP unit $k$

$U R_{k} \quad$ Maximum ramp up rate of CHP unit $k$

$\eta_{m} \quad$ Thermal efficiency of waste heat and energy recovery unit $m$

$F_{m r}^{m i n} \quad$ Minimum allowable generation rate of the $r$ level of steam from waste heat and energy recovery unit $m$

$F_{m r}^{\max } \quad$ Maximum allowable generation rate of the $r$ level of steam from waste heat and energy recovery unit $m$

$P_{m}^{\min } \quad$ Minimum electricity generation rate from waste heat and energy recovery unit $m$

$P_{m}^{\max } \quad$ Maximum electricity generation rate from waste heat and energy recovery unit $m$ 
$D R_{m} \quad$ Maximum ramp down rate of waste heat and energy recovery unit $m$

$U R_{m} \quad$ Maximum ramp up rate of waste heat and energy recovery unit $m$

$P_{t}^{i m p, \max } \quad$ Maximum allowable electricity purchased from the grid during period $t$

$P_{t}^{\text {exp,max }}$ Maximum allowable electricity sold to the grid during period $t$

$\operatorname{In} v_{q}^{N} \quad$ Normal inventory level of gasholder $q$

$\operatorname{In} v_{q}^{L} \quad$ Lowe inventory level of safe operational region in gasholder $q$

$\operatorname{Inv} v_{q}^{H} \quad$ High inventory level of safe operational region in gasholder $q$

$\operatorname{In} v_{q}^{\min } \quad$ Minimum inventory level of gasholder $q$

$\operatorname{In} v_{q}^{\max } \quad$ Maximum inventory level of gasholder $q$

$F_{i q} \quad$ Inlet flow rate of a burner for the $q$ type of byproduct gas in boiler $i$

$\mathrm{NO}_{i q} \quad$ Initial number of burners whose status is on for the $q$ type of byproduct gas in boiler $i$

$F_{u q}^{\min } \quad$ Minimum flow rate of the $q$ type of fuel required in production unit $u$

$F_{u q}^{\max } \quad$ Maximum flow rate of the $q$ type of fuel required in production unit $u$

$H V_{u}^{\min } \quad$ Minimum heating value required in production unit $u$

$C_{q} \quad$ Price of the $q$ type of fuel

$C_{t}^{e x p} \quad$ Electricity sale price in period $t$

$C_{t}^{i m p} \quad$ Electricity purchase price in period $t$

$W_{q}^{\text {emission }} \quad$ Penalty coefficient for gas emission of the $q$ type of byproduct gas

$W_{q}^{L} \quad$ Penalty coefficient for the inventory level in gasholder $q$ which lies in its low operational region

$W_{q}^{H} \quad$ Penalty coefficient for the inventory level in gasholder q which lies in its high operational region

$W_{q}^{d^{-}} \quad$ Penalty coefficient for the deviation below the normal operational level in gasholder $q$

$W_{q}^{d^{+}} \quad$ Penalty coefficient for the deviation above the normal operation level in gasholder $q$

$W_{q}^{S W} \quad$ Penalty coefficient for burner switching operations for the $q$ type of byproduct gas

$W_{q}^{2 S} \quad$ Penalty coefficient for simultaneously switching two burners related to the $q$ type of byproduct gas in a boiler

$W_{q}^{3 S} \quad$ Penalty coefficient for simultaneously switching three burners related to the $q$ type of byproduct gas in a boiler 
$C_{i}^{M} \quad$ Maintenance cost of boiler $i$

$C_{j}^{P M} \quad$ Maintenance cost of turbine $j$

$C_{k}^{P M} \quad$ Maintenance cost of CHP unit $k$

$C_{m}^{P M} \quad$ Maintenance cost of waste heat and energy recovery unit $m$

\section{Positive Variables}

$F_{i q t} \quad$ Flow rate of the $q$ type of fuel fed into boiler $i$ in period $t$

$F_{\text {irt }} \quad$ Flow rate of the $r$ level of steam generated from boiler $i$ in period $t$

$F_{i t}^{w} \quad$ Flow rate of water used in boiler $i$ in period $t$

$F_{j r t}^{i n} \quad$ Flow rate of the $r$ level of steam into turbine $j$ in period $t$

$F_{j r t}^{o u t} \quad$ Flow rate of the $r$ level of steam generated from turbine $j$ in period $t$

$F_{j t}^{e x h} \quad$ Flow rate of exhaust steam generated from turbine $j$ during period $t$

$P_{j t} \quad$ Power generation rate from turbine $j$ during time period $t$

$F_{k r t} \quad$ Flow rate of the $r$ level of steam generated from CHP unit $k$ in period $t$

$F_{k q t} \quad$ Flow rate of the $q$ type of fuel consumed in CHP unit $k$ during period $t$

$P_{k t} \quad$ Electric power generation rate from CHP unit $k$ during period $t$

$F_{m r t} \quad$ Flow rate of the $r$ level of steam generated from waste heat and energy recovery unit $m$ in period $t$

$E_{m t}^{i n} \quad$ Amount of waste heat and energy recovered in waste heat and energy recovery unit $m$ in period $t$

$P_{m t} \quad$ Electric power generation rate from waste heat and energy recovery unit $m$ in period $t$

$P_{t}^{\text {dem }} \quad$ Electricity demand from production units in period $t$

$P_{t}^{i m p} \quad$ Electricity purchased from the grid in period $t$

$P_{t}^{\exp } \quad$ Electricity sold to the grid in period $t$

$D_{r t}^{d e m} \quad$ Demand of the $r$ level of steam required in production units in period $t$

$F_{q t}^{G e n} \quad$ Generation rate of the $q$ type of byproduct gas in period $t$

Inv $v_{q t} \quad$ Inventory level of byproduct gas in gasholder $q$ at the end of period $\mathrm{t}$

$F_{\text {uqt }} \quad$ Flow rate of the $q$ type of byproduct gas consumed in production unit $u$ in period $t$

$Q_{q t}^{\text {emission }} \quad$ Amount of byproduct gas emission at gasholder $q$ during period $t$

$N_{\text {iqt }} \quad$ Number of burners related to the $q$ type of byproduct gas whose status is on in period $t$

$\Delta N_{i q t} \quad$ Number of burners related to the $q$ type of byproduct gas whose status is changed in period 
$t$

$D_{u q t}^{d e m} \quad$ Demand of the $q$ type of byproduct gas required in production unit $u$ during period $t$

$E_{u t}^{\text {Dem }} \quad$ Energy demand in production unit $u$ during period $t$

$\operatorname{SInv} v_{q t}^{d^{+}} \quad$ Deviation above the normal inventory level of gasholder $q$ in period $t$

$\operatorname{SIn} v_{q t}^{d^{-}} \quad$ Deviation below the normal inventory level of gasholder $q$ in period $t$

$\operatorname{SIn} v_{q t}^{L} \quad$ Violation of the low inventory level of safe operational region in gasholder $q$ in period $t$

$\operatorname{SInv} v_{q t}^{H} \quad$ Violation of the high inventory level of safe operational region in gasholder $q$ in period $t$

\section{0-1 Continuous Variables}

$y_{P t}^{\exp } \quad 1$ if electricity $P$ is sold to the grid in period $t$

$i b n 0_{i q t} \quad 1$ if no burner related to the $q$ type of byproduct gas changes its status in period $t$

\section{Binary Variables}

$y_{P, t}^{i m p} \quad 1$ if electricity $P$ is purchased from the grid in period $t$

$i b n 1_{i q t}^{+} \quad 1$ if only one burner related to the $q$ type of byproduct gas changes its status in period $t$

$i b n 2_{i q t}^{+} \quad 1$ if two burners related to the $q$ type of byproduct gas change their status in period $t$

$i b n 3_{i q t}^{+} \quad 1$ if three burners related to the $q$ type of byproduct gas change their status in period $t$ 


\section{REFERENCES}

[1] International Energy Agency (IEA). Energy balance flows, http://www.iea.org/Sankey/index.html; 2017 [ accessed 12 June 2017].

[2] Jin P, Jiang Z, Bao C, Hao S, Zhang X. The energy consumption and carbon emission of the integrated steel mill with oxygen blast furnace. Resources Conservation \& Recycling 2017; 117: $58-65$.

[3] Zhang S, Worrell E, Crijns-Graus W, Wagner F, Cofala J. Co-benefits of energy efficiency improvement and air pollution abatement in the Chinese iron and steel industry. Energy 2014; 78 : 333-345.

[4] Liu X, Chen L, Feng H, Qin X, Sun F. Constructal design of a blast furnace iron-making process based on multi-objective optimization. Energy 2016; 109: 137-151.

[5] Li J, Xiao X, Tang Q, Floudas C. Production Scheduling of a Large-Scale Steelmaking Continuous Casting Process via Unit-Specific Event-Based Continuous-Time Models: ShortTerm and Medium-Term Scheduling. Industrial \& Engineering Chemistry Research 2012; 51(21): 7300-7319.

[6] Tang L, Meng Y, Chen ZL, Liu J. Coil Batching to Improve Productivity and Energy Utilization in Steel Production. Manufacturing \& Service Operations Management 2016; 18(2): 62-79.

[7] Arens M, Worrell E, Schleich J. Energy intensity development of the German iron and steel industry between 1991 and 2007. Energy 2012; 45(1): 786-797.

[8] Ansari N, Seifi A. A system dynamics analysis of energy consumption and corrective policies in Iranian iron and steel industry. Energy 2012; 43(1): 334-343.

[9] Zhang J, Wang G. Energy saving technologies and productive efficiency in the Chinese iron and steel sector. Energy 2008; 33(4): 525-537.

[10]He F, Zhang Q, Lei J, Fu W, Xu X. Energy efficiency and productivity change of China's iron and steel industry: Accounting for undesirable outputs. Energy Policy 2013; 54(54): 204-213.

[11]Hasanbeigi A, Morrow W, Sathaye J, Masanet E, Xu T. A bottom-up model to estimate the energy efficiency improvement and CO 2 emission reduction potentials in the Chinese iron and steel industry. Energy 2013; 50(1): 315-325.

[12]Lin B, Wang X. Promoting energy conservation in China's iron \& steel sector. Energy 2014; 73: 465-474.

[13]Akimoto K, Sannomiya N, Nishikawa Y, Tsuda T. An Optimal Gas Supply for a Power Plant Using a Mixed Integer Programming Model. Automatica 1991; 27(3): 513-518.

[14]Kim JH, Yi HS, Han C. A Novel MILP Model for Plantwide Multiperiod Optimization of byproduct Gas Supply System in the Iron- and Steel-Making Process. Chemical Engineering 
Research and Design 2003; 81(8): 1015-1025.

[15]Kong H, Qi E, Li H, Li G, Zhang X. An MILP Model for Optimization of Byproduct Gases in the Integrated Iron and Steel Plant. Applied Energy 2010; 87(7): 2156-2163.

[16]Zhang Q, Ti W, Cai JJ, Du T, Wang AH. Multi-Period Optimal Distribution Model of Energy Medium and Its Application. International Journal of Iron and Steel Research 2011; 18(8): 37-41.

[17]Zhao X, Bai H, Lu X, Shi Q, Han J. A MILP Model Concerning the Optimization of Penalty Factors for the Short-term Distribution of Byproduct Gases Produced in the Iron and Steel Making Process. Applied Energy 2015; 148(2): 142-158.

[18]de Oliveira Junior VB, Pena JGC, Salles JLF. An improved plant-wide multiperiod optimization model of a byproduct gas supply system in the iron and steel-making process. Applied Energy 2016; 164(3): 462-474.

[19]Zeng Y, Sun Y. Short-term Scheduling of Steam Power System in Iron and Steel Industry under Time-of-use Power Price. International Journal of Iron and Steel Research 2015; 22(9): 795-803.

[20]Yang J, Cai J, Sun W, Huang J. Optimal allocation of surplus gas and suitable capacity for buffer users in steel plant. Applied Thermal Engineering 2017; 115: 586-596.

[21]Li J, Karimi IA, Srinivasan R. Recipe determination and scheduling of gasoline blending operations. Aiche Journal 2010; 56(2): 441-465.

[22]Li J, Karimi IA. Scheduling Gasoline Blending Operations from Recipe Determination to Shipping Using Unit Slots. Industrial \& Engineering Chemistry Research 2011; 50(15): 91569174.

[23]Aguilar O, Perry SJ, Kim JK, Smith R. Design and Optimization of Flexible Utility Systems Subject to Variable Conditions: Part 1: Modelling Framework. Chemical Engineering Research and Design 2007; 85(8): 1136-1148.

[24]Mitra S, Sun L, Grossmann IE. Optimal Scheduling of Industrial Combined Heat and Power Plants under Time-sensitive Electricity Prices. Energy 2013; 54(1): 194-211.

[25]Bischi A, Taccari L, Martelli E, Amaldi E, Manzolini G, Silva P, Campanari S, Macchi E. A detailed MILP optimization model for combined cooling, heat and power system operation planning. Energy 2014; 74(5): 12-26.

[26]Kim JS, Edgar TF. Optimal Scheduling of Combined Heat and Power Plants Using MixedInteger Nonlinear Programming. Energy 2014; 77(1): 675-690. 


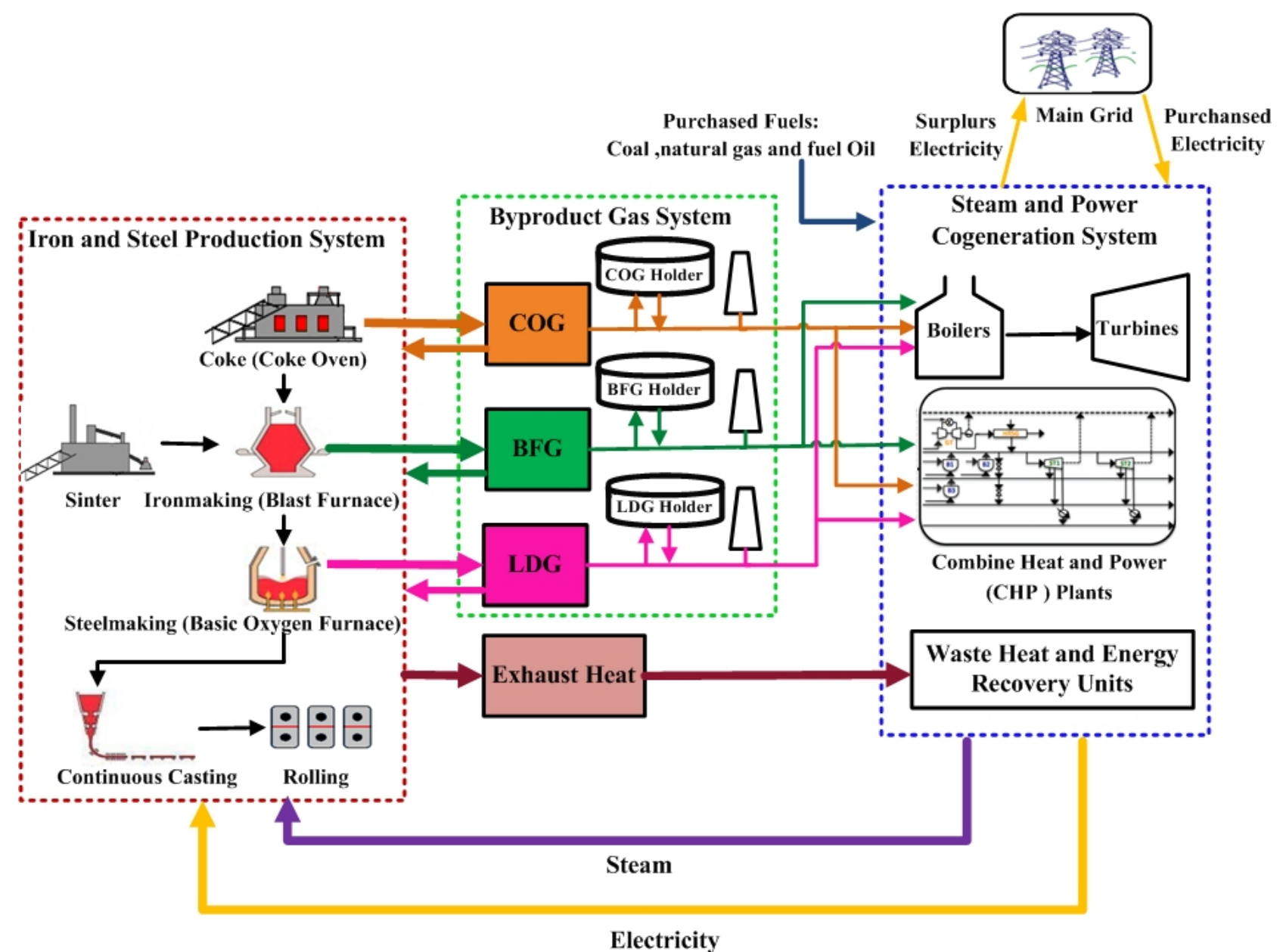

Figure 1 Distribution of byproduct gases, steam and electricity in a typical iron and steel plant 


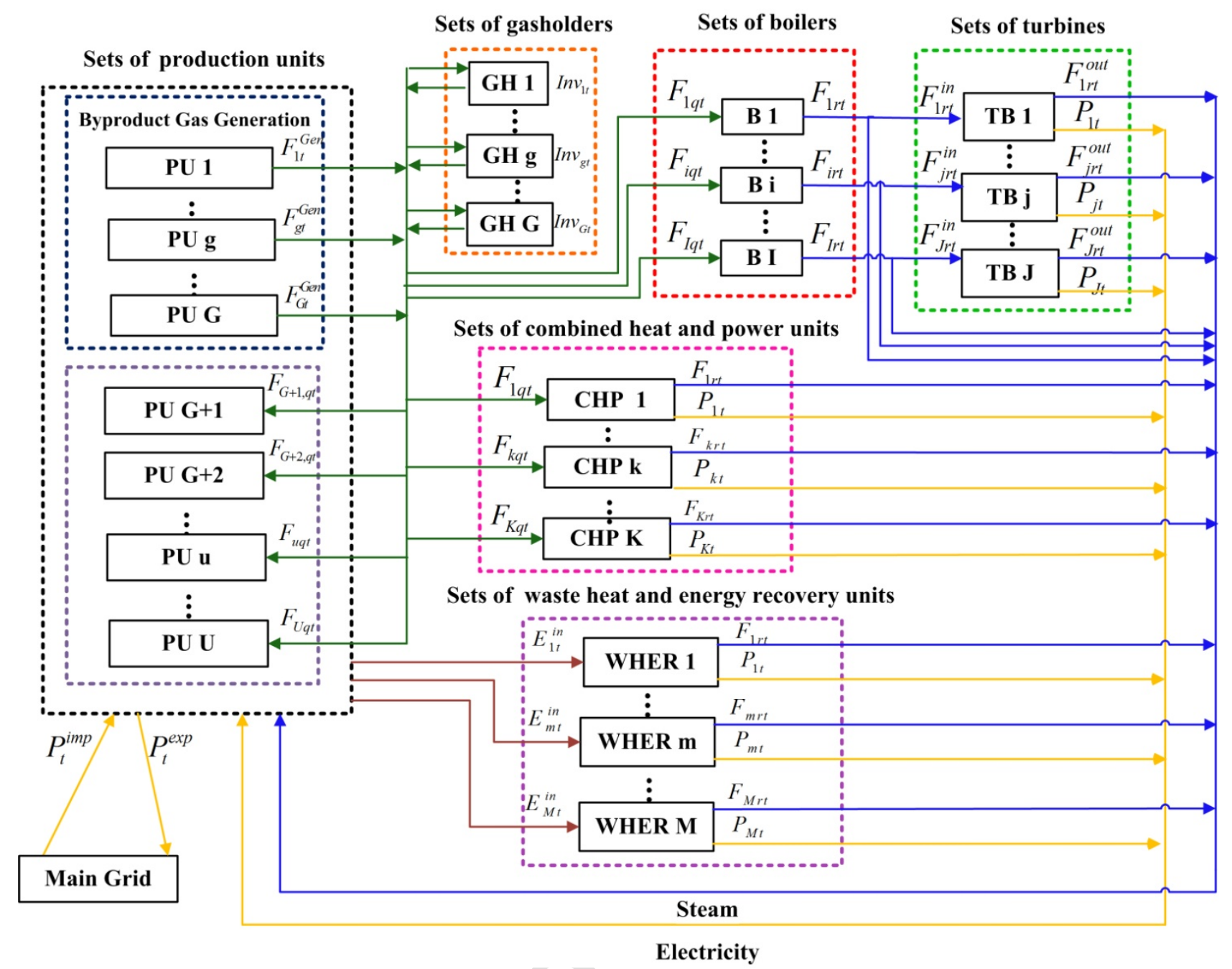

Figure 2 The superstructure for byproduct gas, steam and electricity generation and distribution in a typical iron and steel plant 


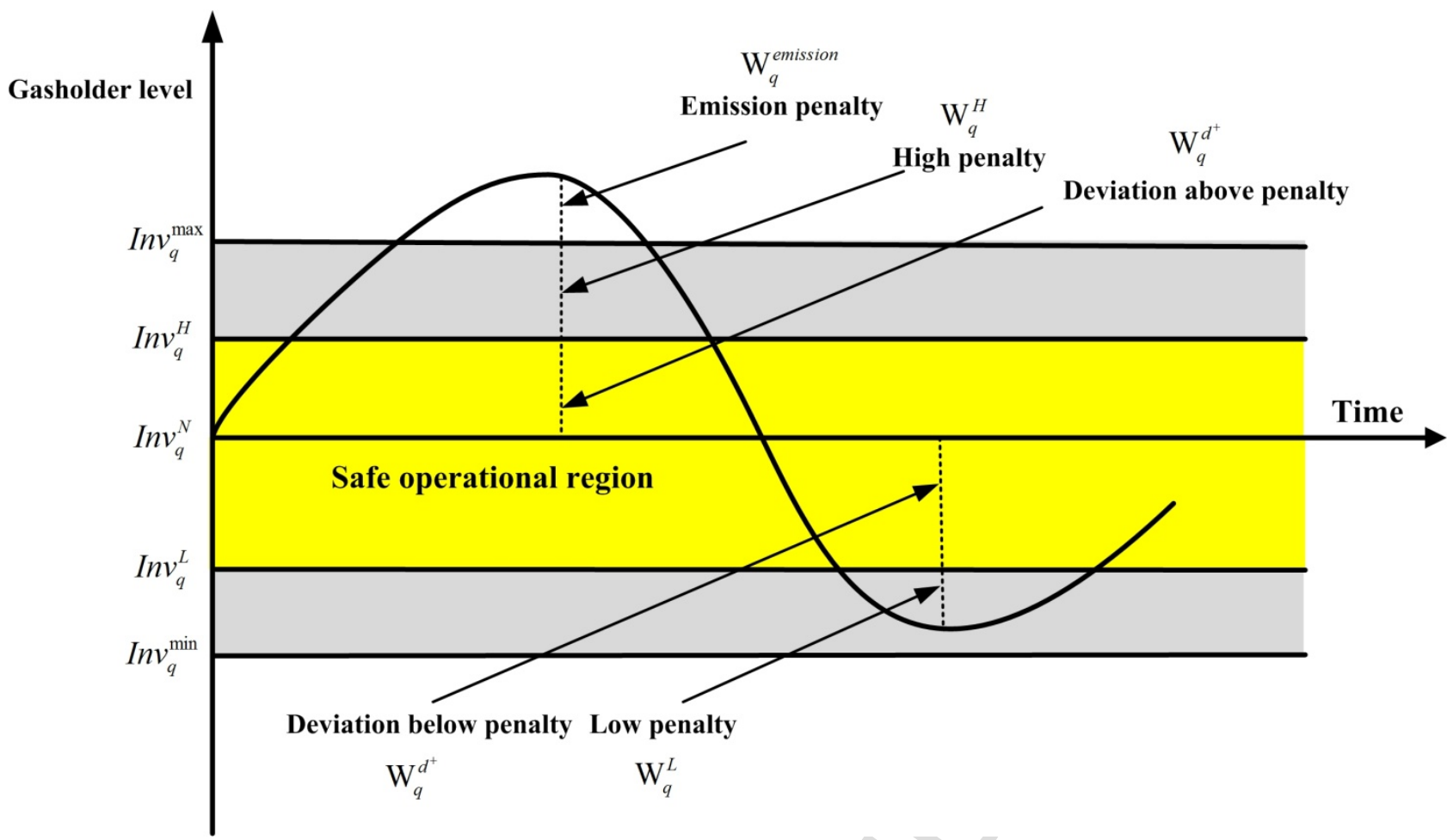

Figure 3 Illustration of the normal operating point, safe operational zone and penalties in a gasholder 


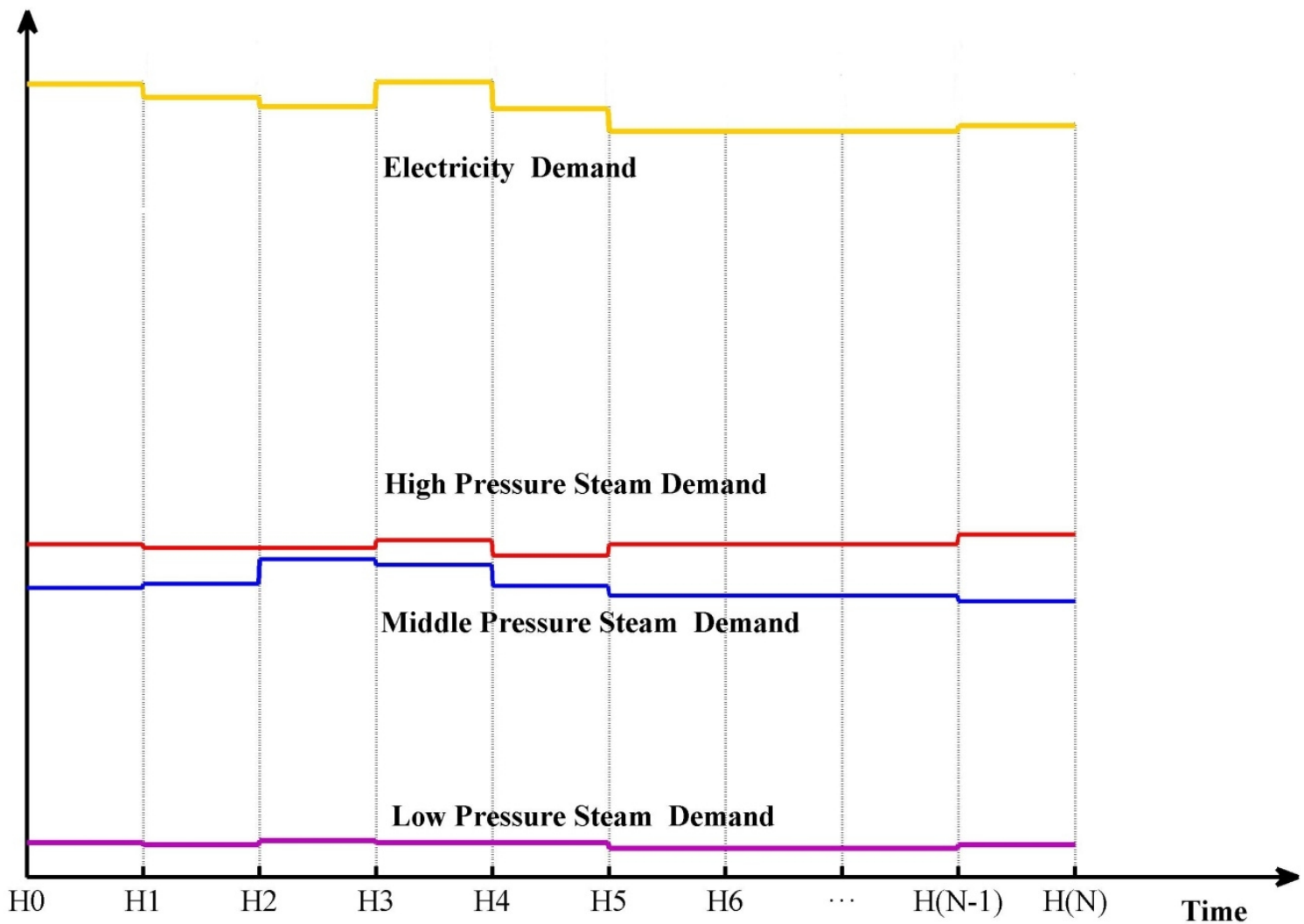

Figure 4 Schematic diagram of period definition 


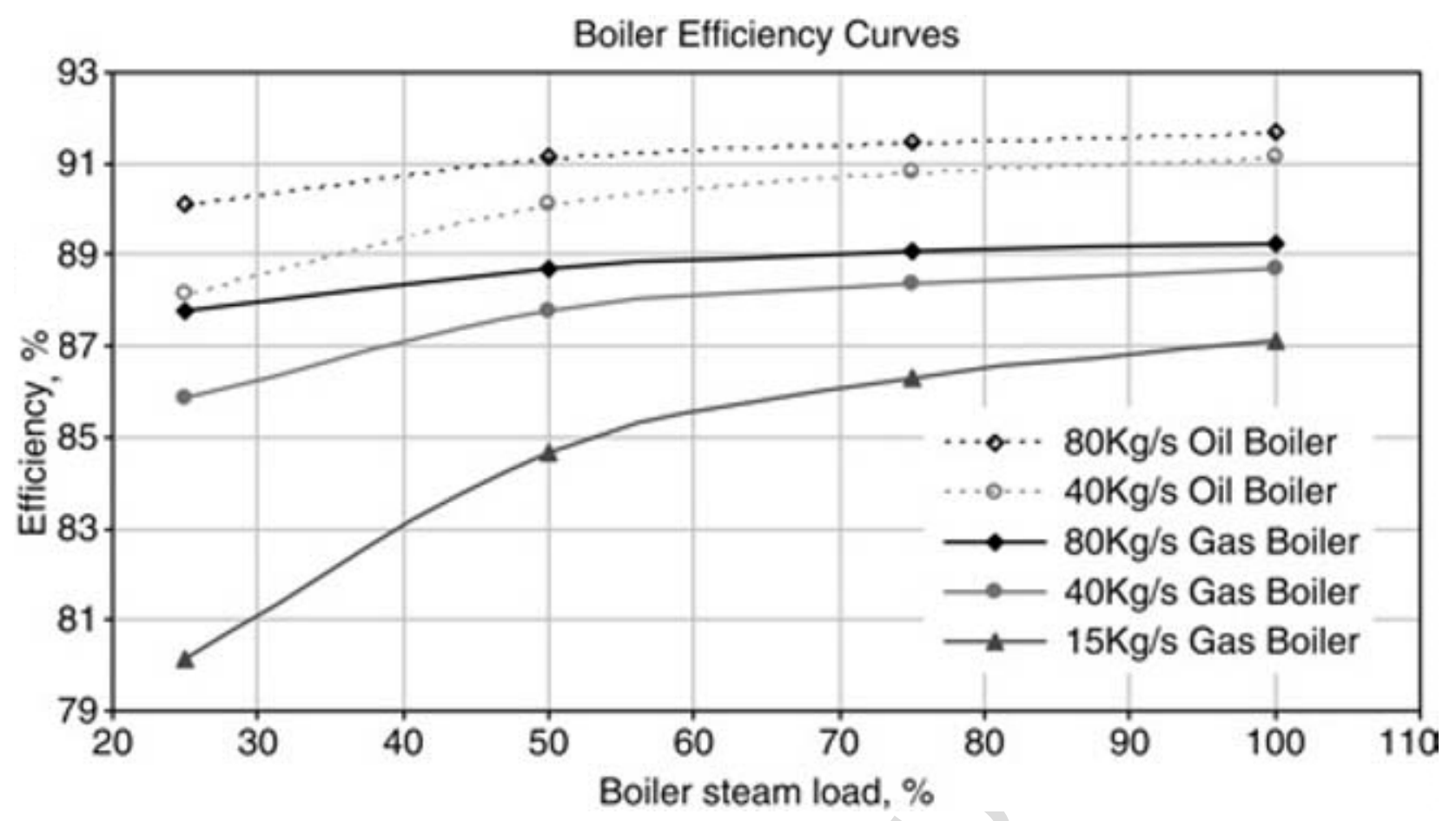

Figure 5 Industrial boiler efficiency curves with different fuel inlet flow rates 


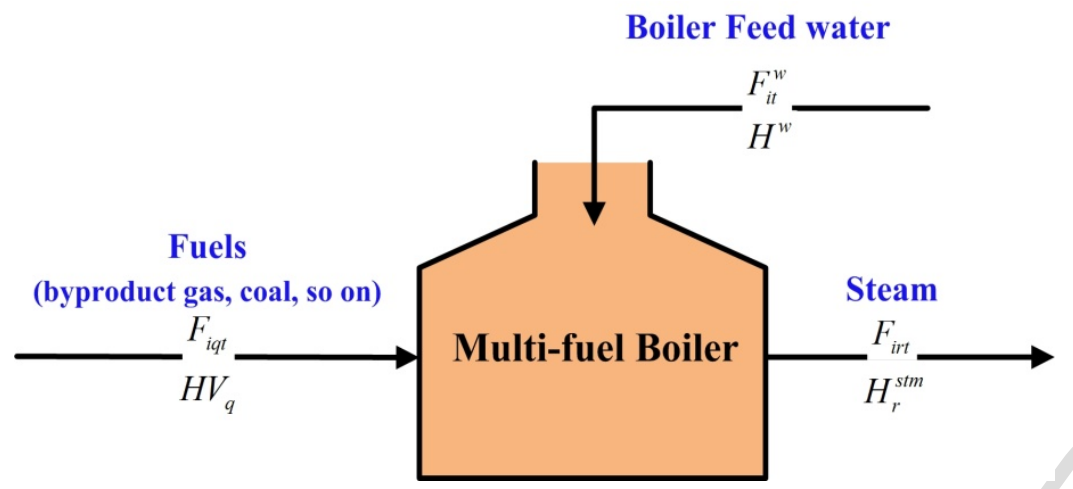

Figure 6 A schematic diagram of a multi-fuel boiler for mass and energy balance illustration 
High or middle pressure steam

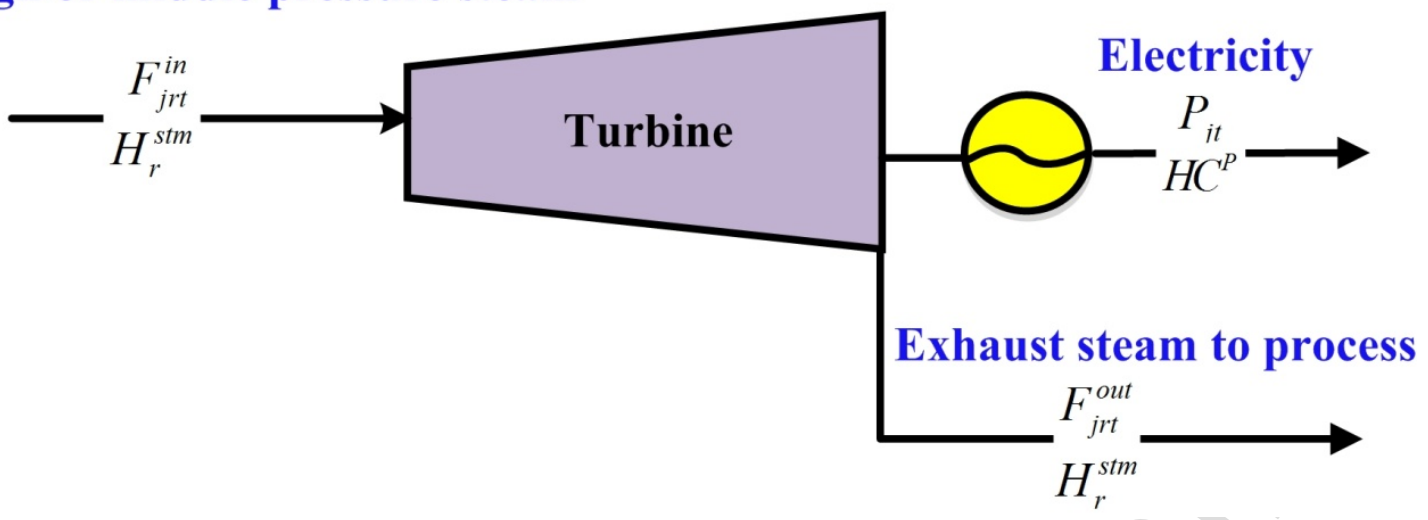

(a) Back pressure turbine

High or middle pressure steam

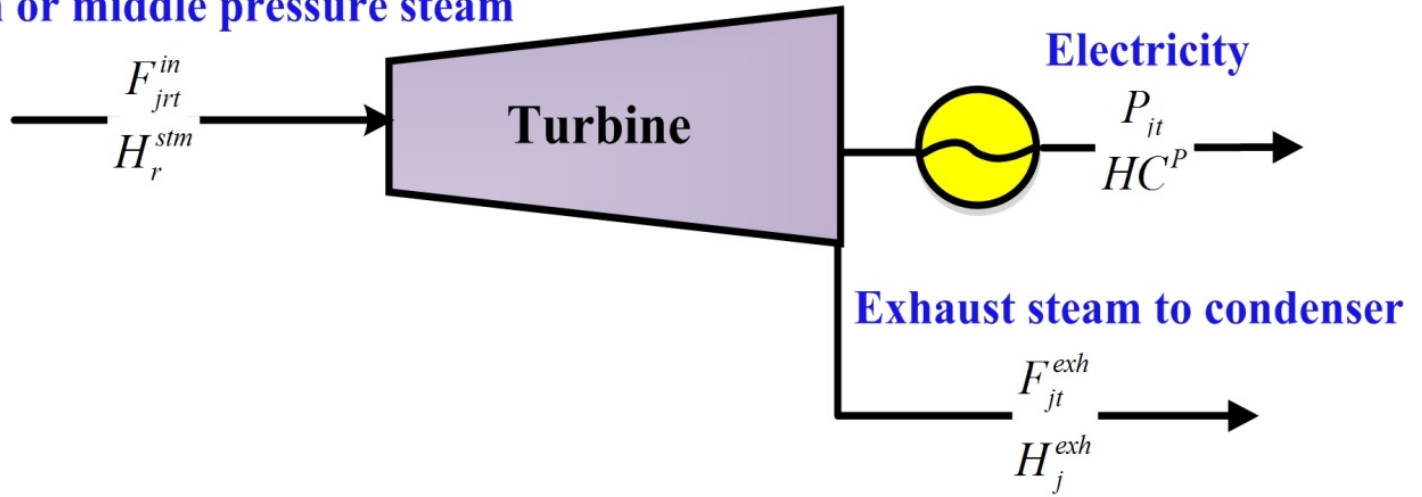

(a) Condensing turbine

High pressure (HP) steam

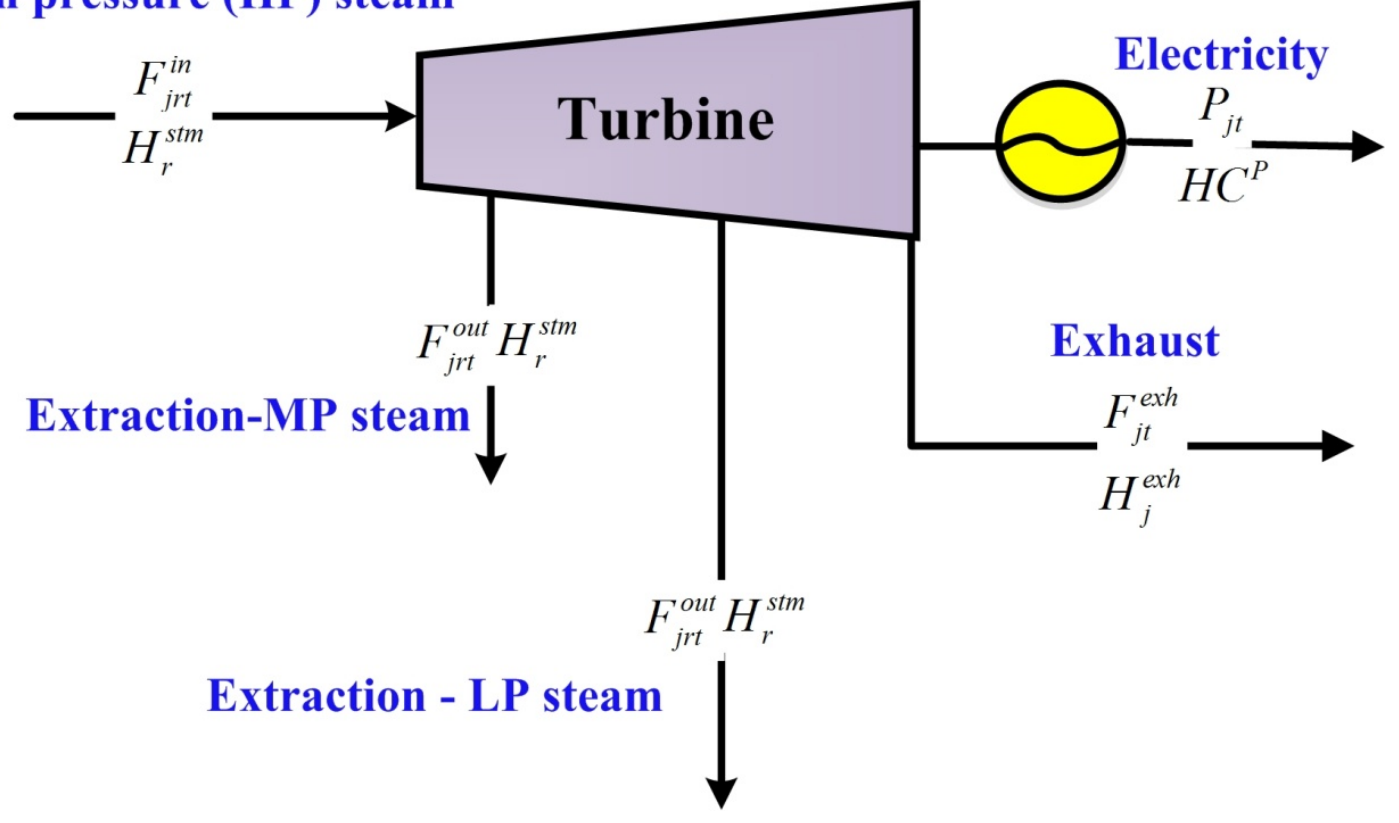

(a) Extraction turbine

Figure 7 Schematic diagram of a steam turbine for steam and electricity balance illustration 


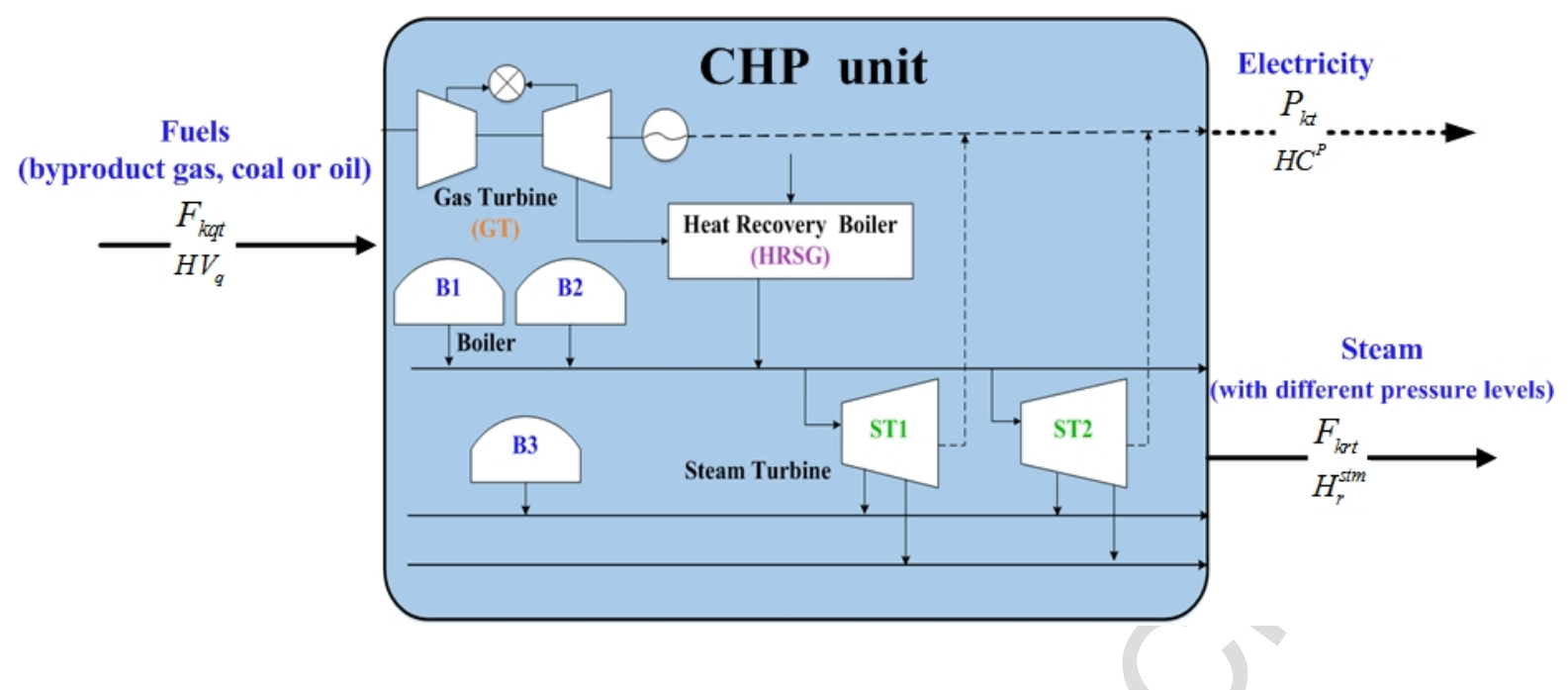

Figure 8 Schematic diagram of a CHP unit for steam and electricity balance illustration 


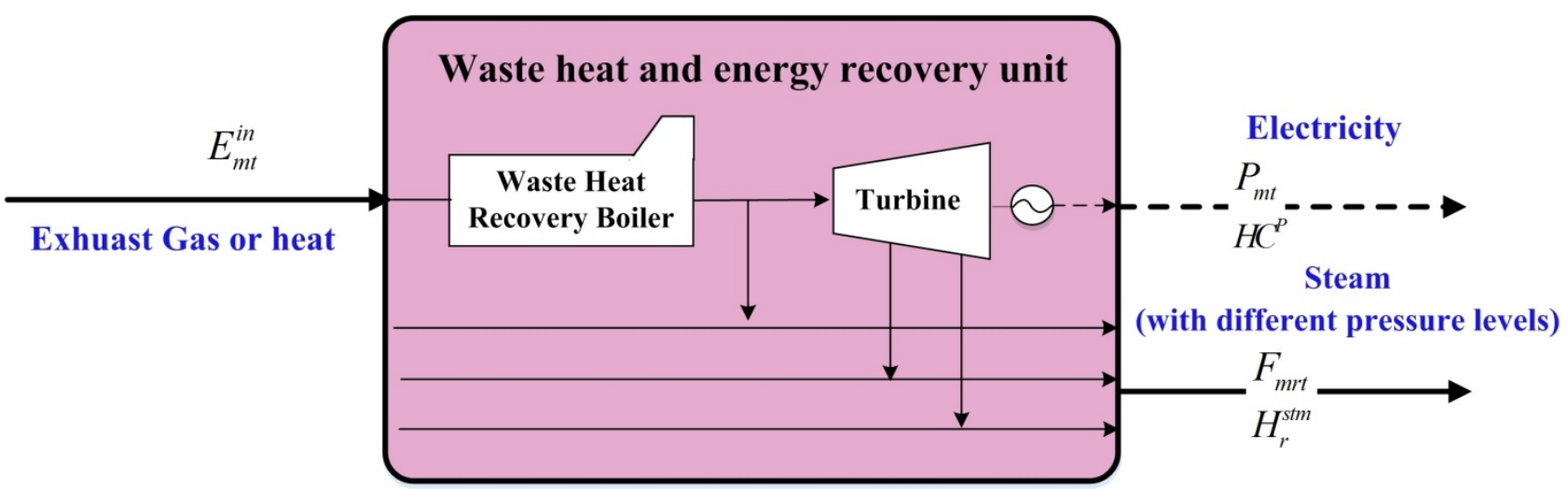

Figure 9 Schematic diagram of a waste heat and energy recovery unit for steam and electricity generation illustration 


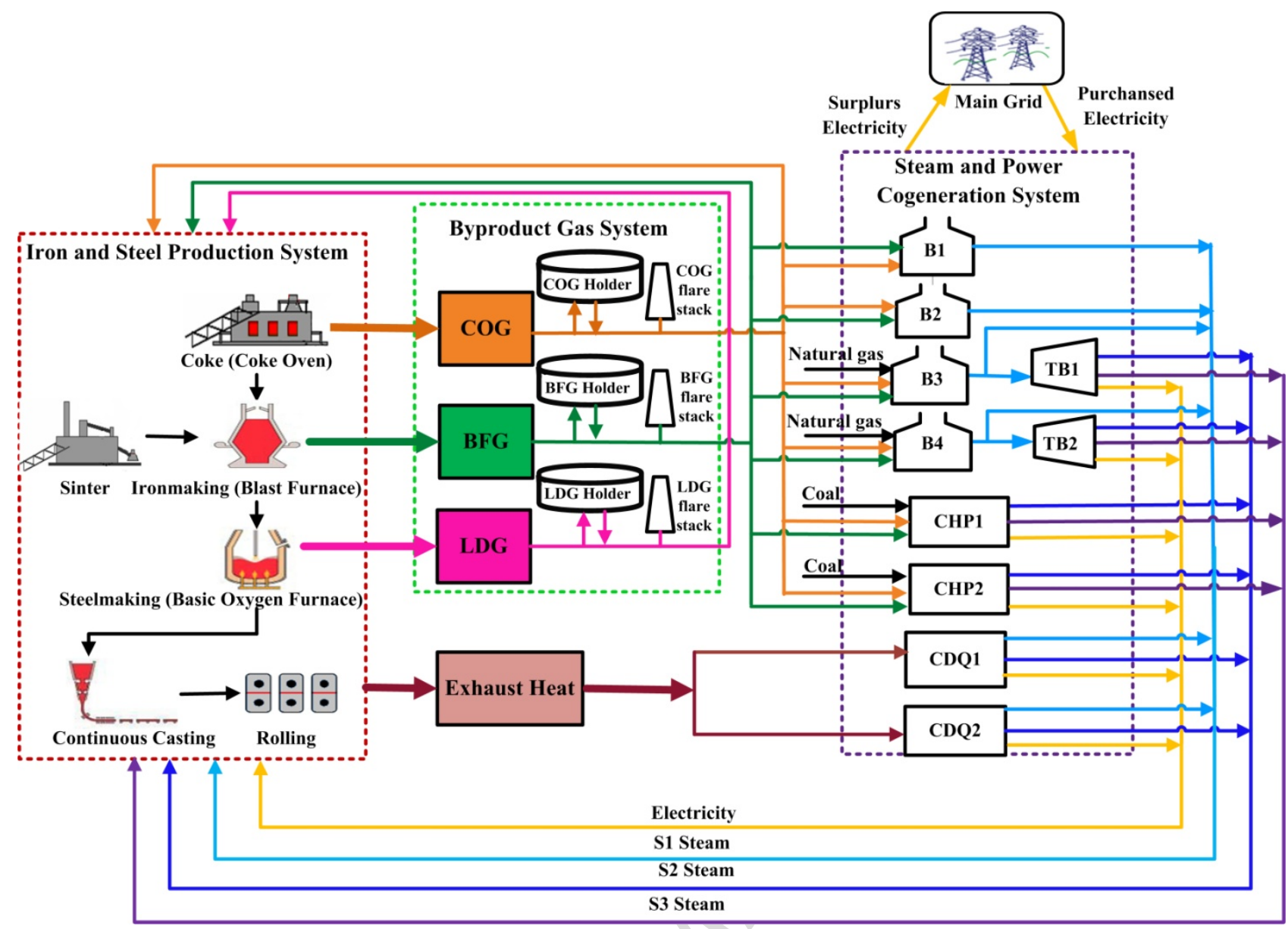

Figure 10 Superstructure of the distribution of byproduct gases, steam and electricity for the industrial example 


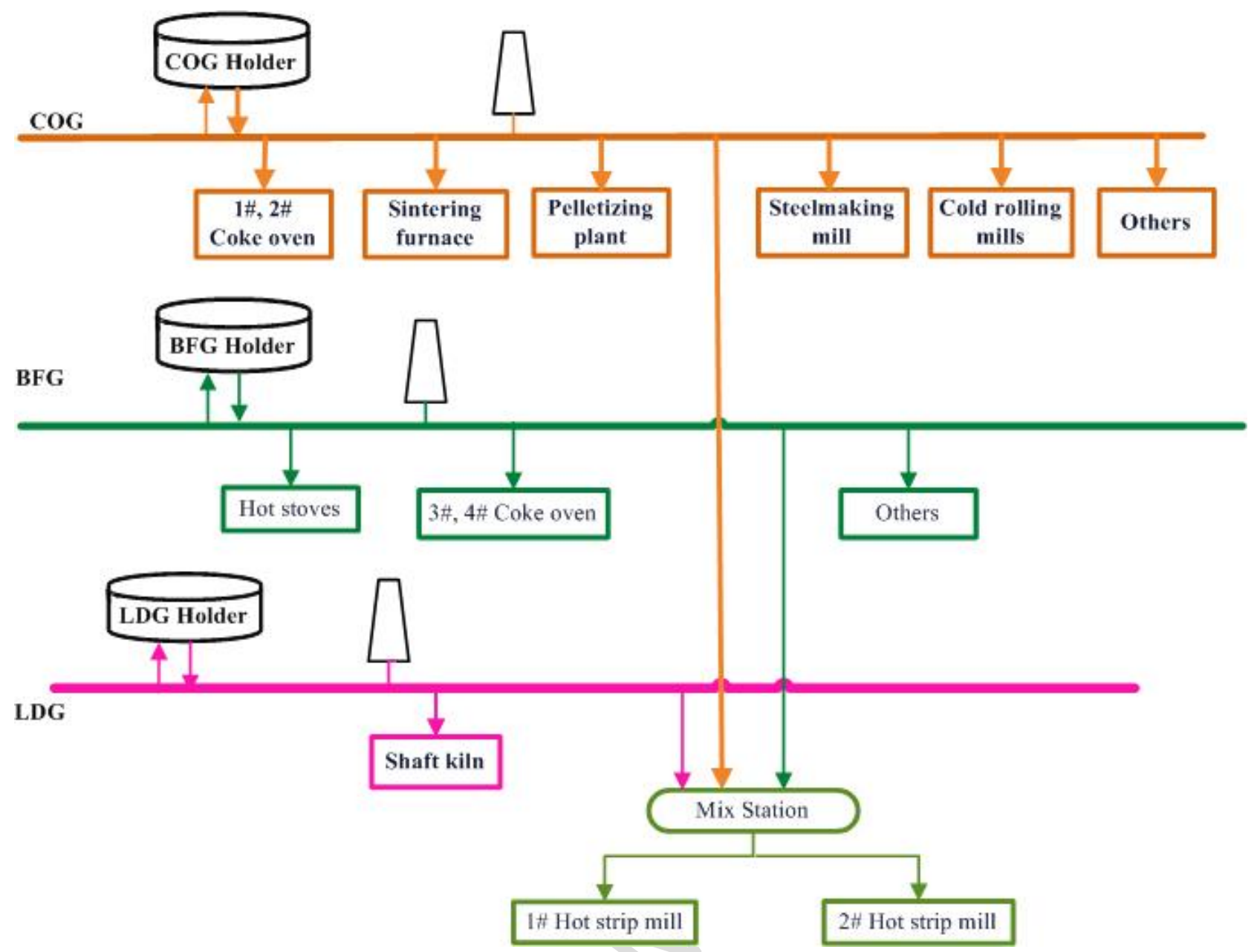

Figure 11 Distribution of byproduct gases in production units for the industrial example 


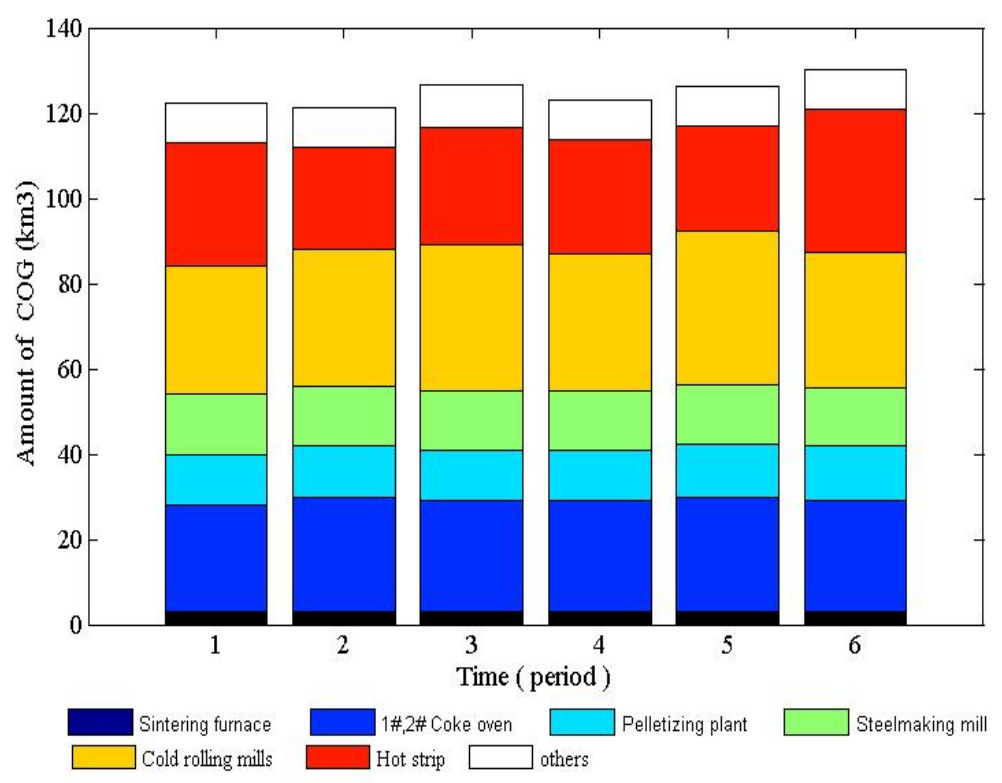

(a) COG distribution

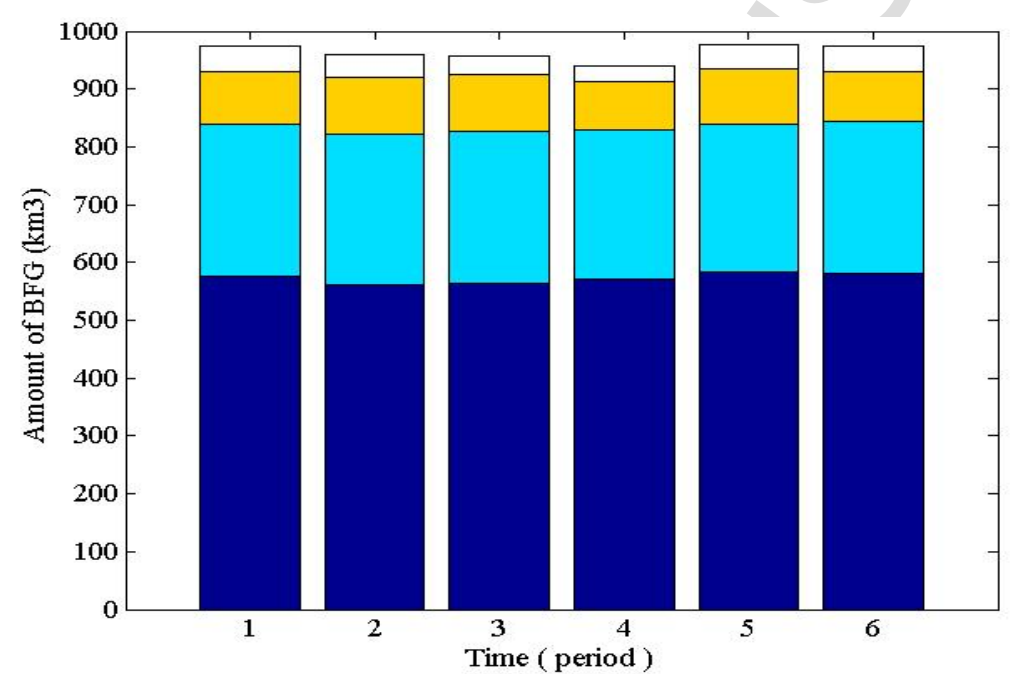

$\square$ Hot stoves $\square$ 3\#,4\# Coke oven $\square$ Hot strip $\square$ others

(b) BFG distribution

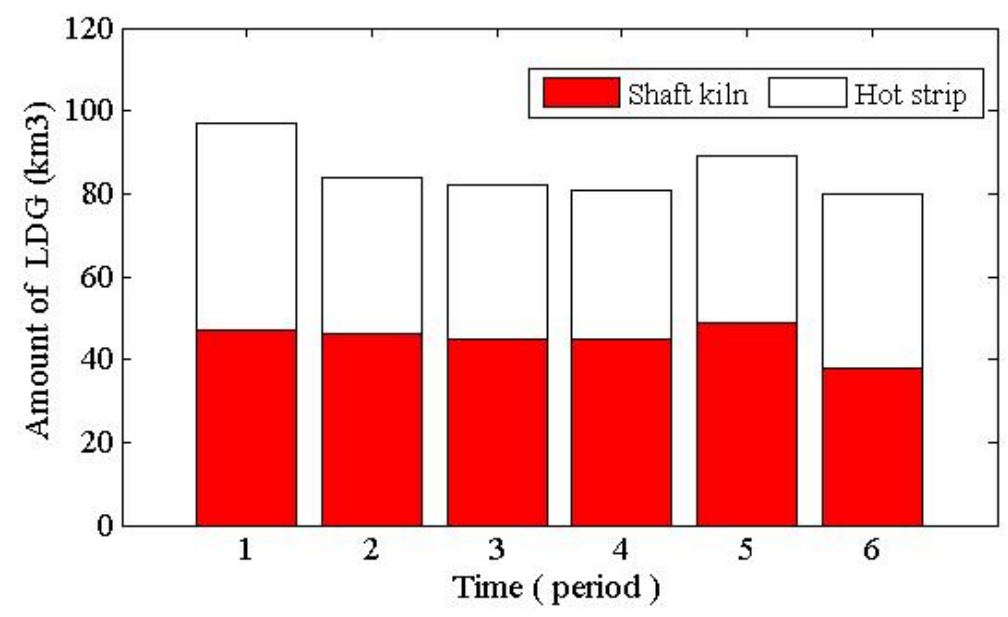

(C) LDG distribution

Figure 12 The optimal distribution of byproduct gases in production units 


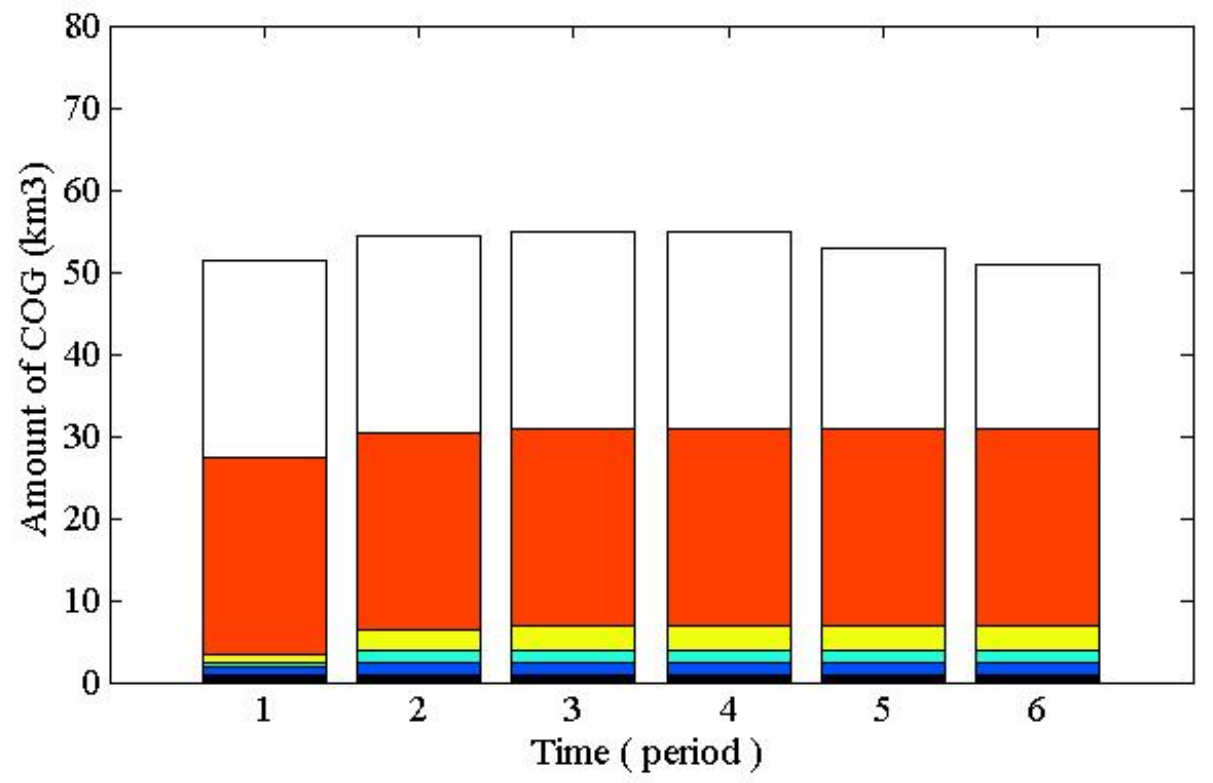

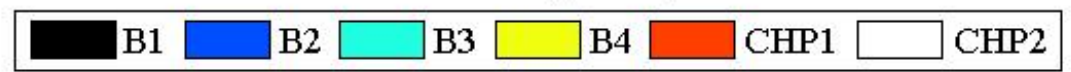

(a) COG distribution

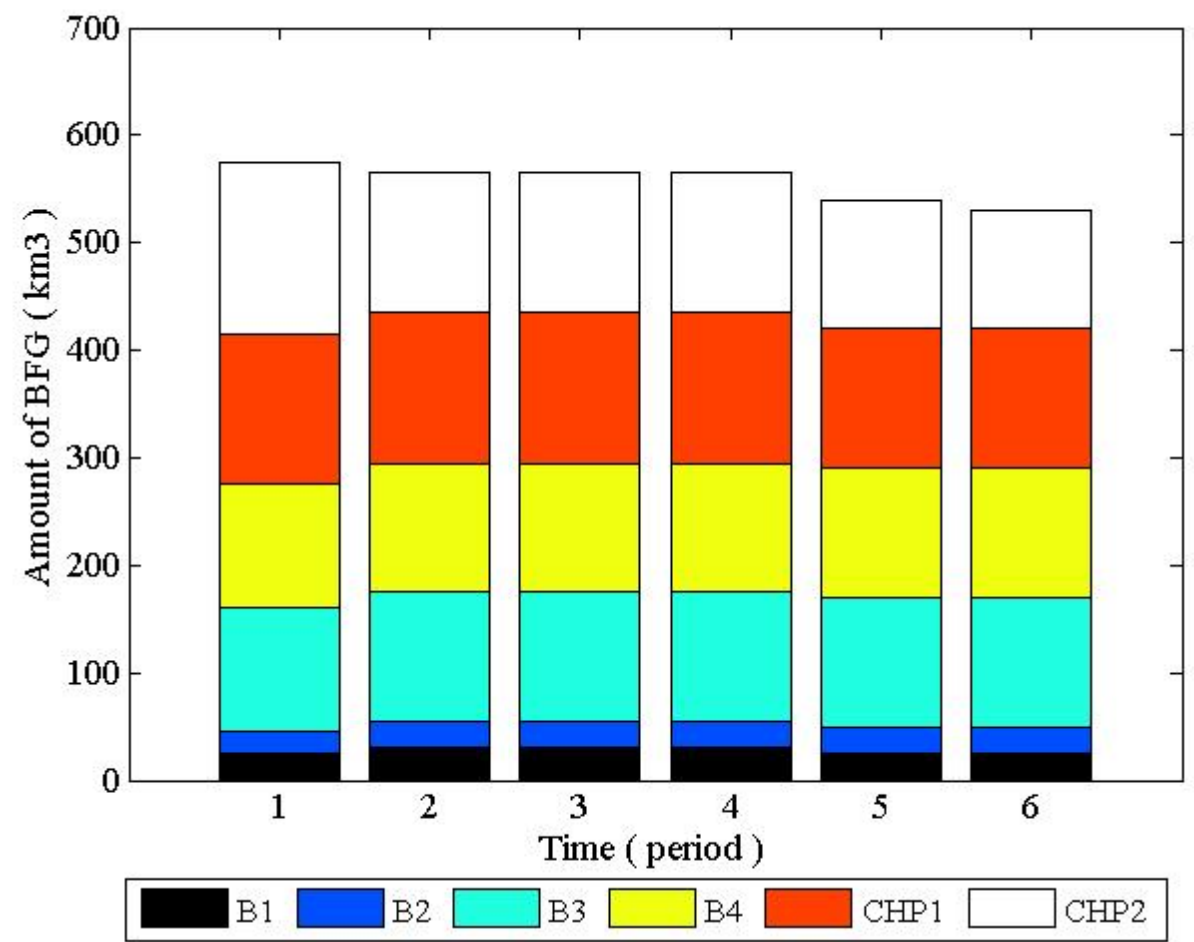

(b) BFG distribution

Figure 13 The optimal distribution of byproduct gases in boilers and CHP units 


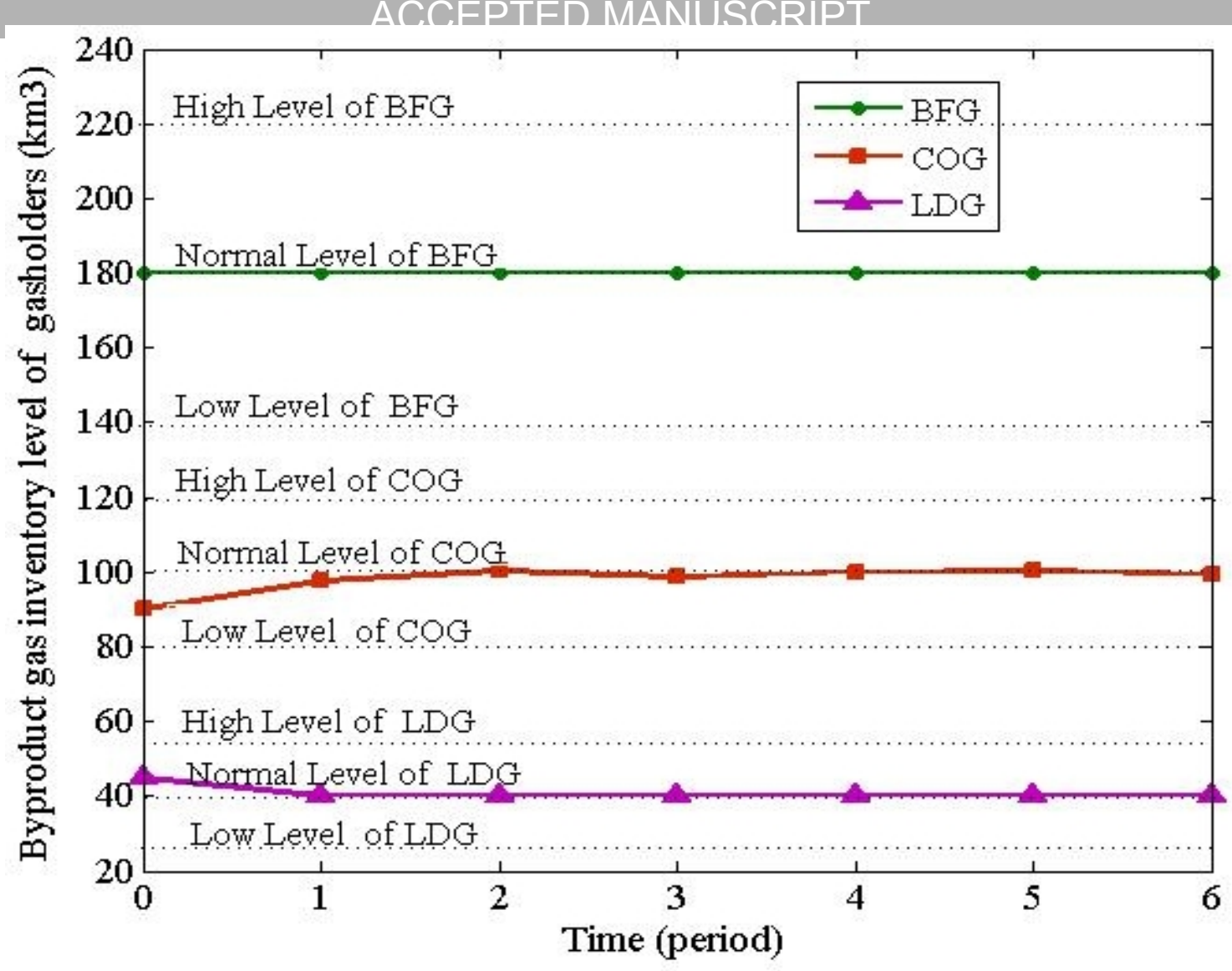

Figure 14 Inventory profiles of COG, BFG and LDG gasholders 


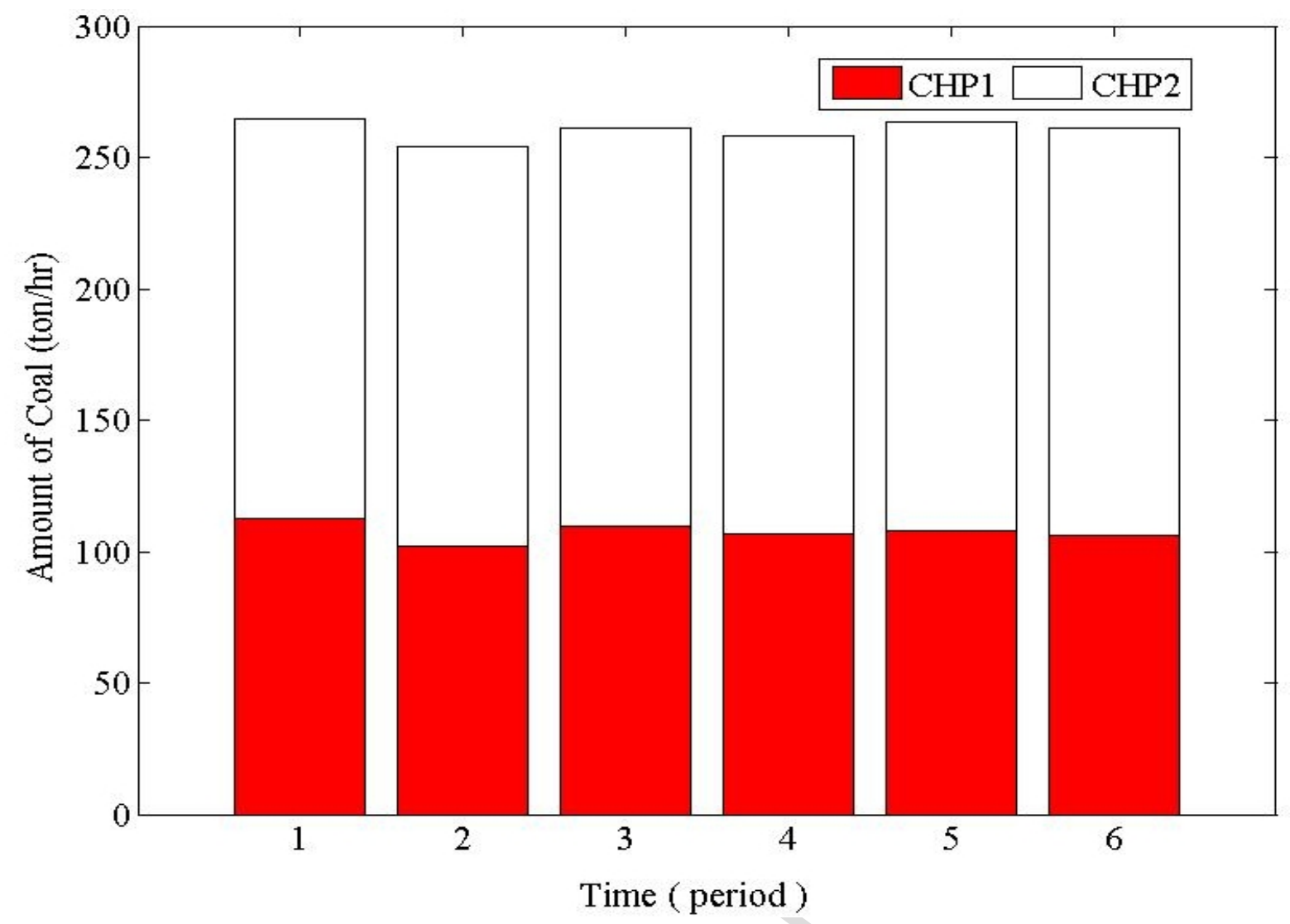

Figure 15 Optimal dispatch of coal in CHP units 


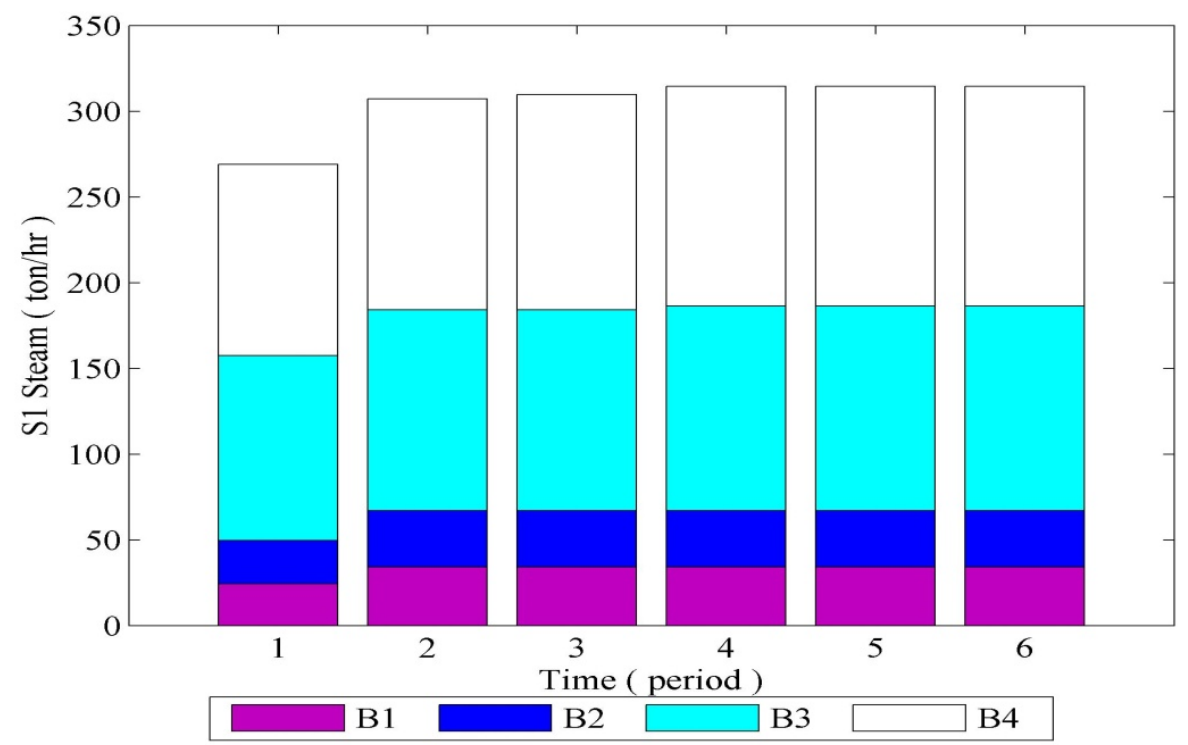

(a) High-pressure steam S1 generation

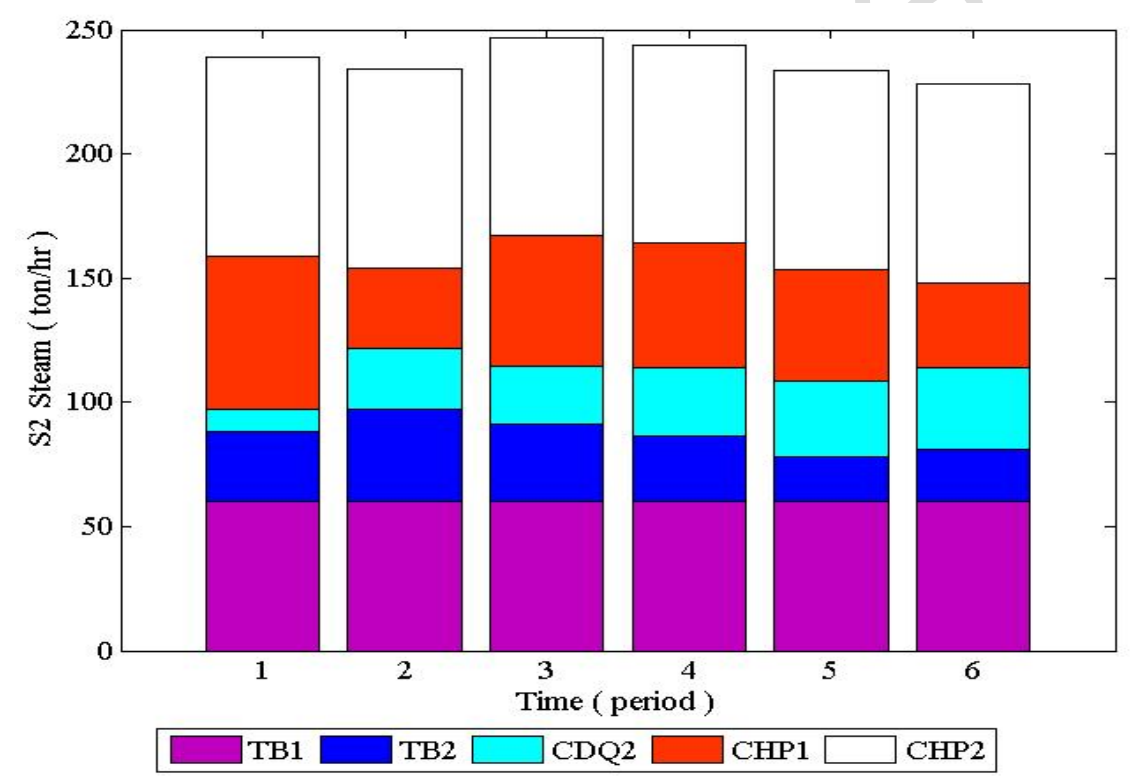

(b) Medium-pressure steam S2 generation

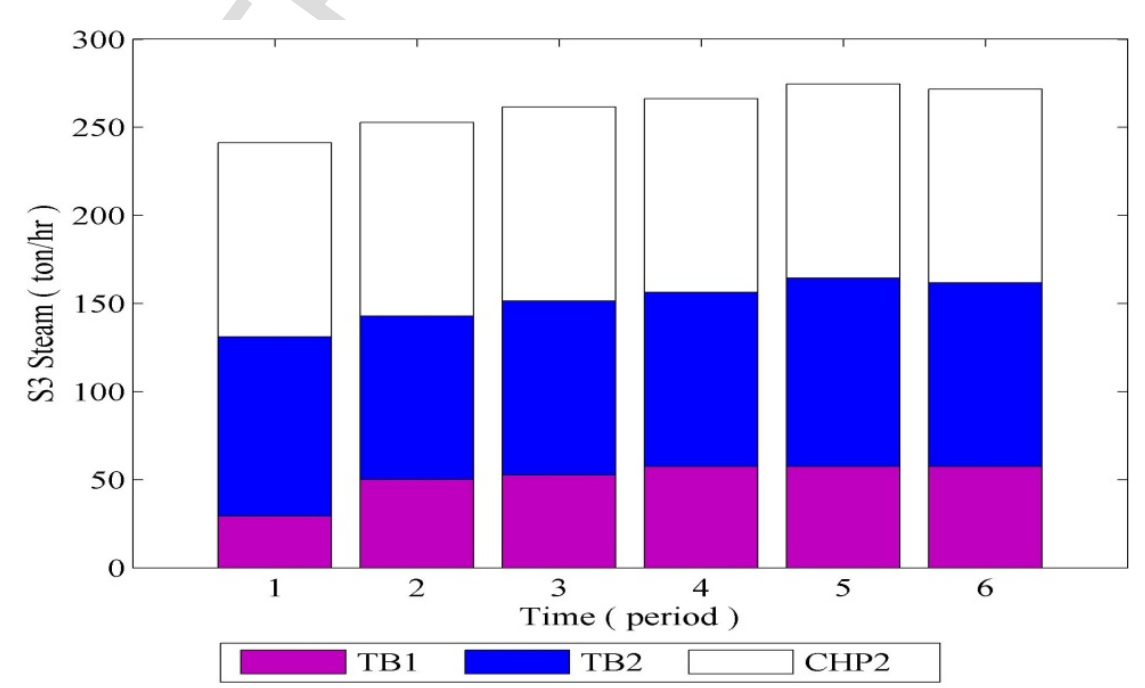

(c) Low-pressure steam S3 generation

Figure 16 Optimal steam generation rates from turbines, CHP and CDQ units 


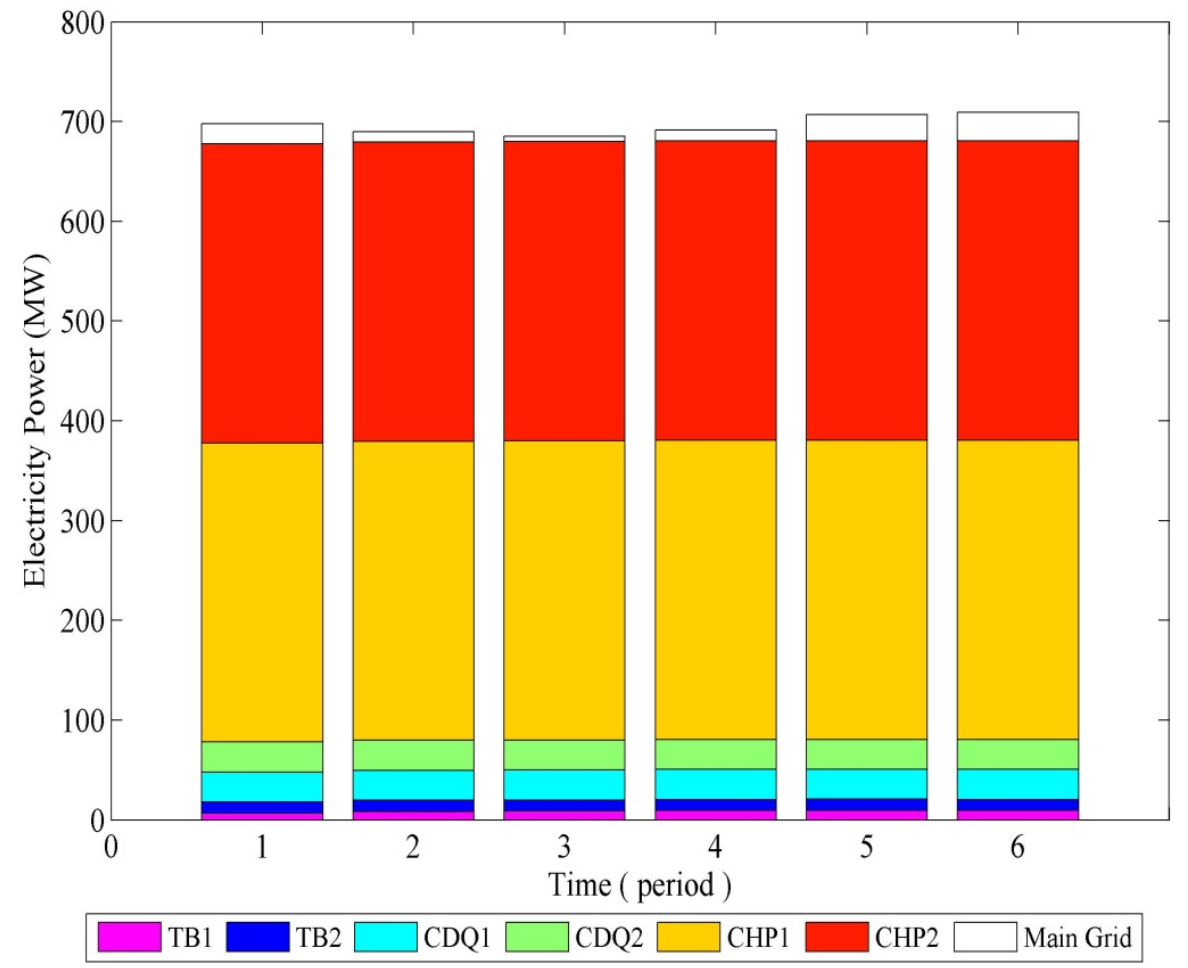

Figure 17 Optimal electricity generation rates from turbines, CHP and CDQ units 


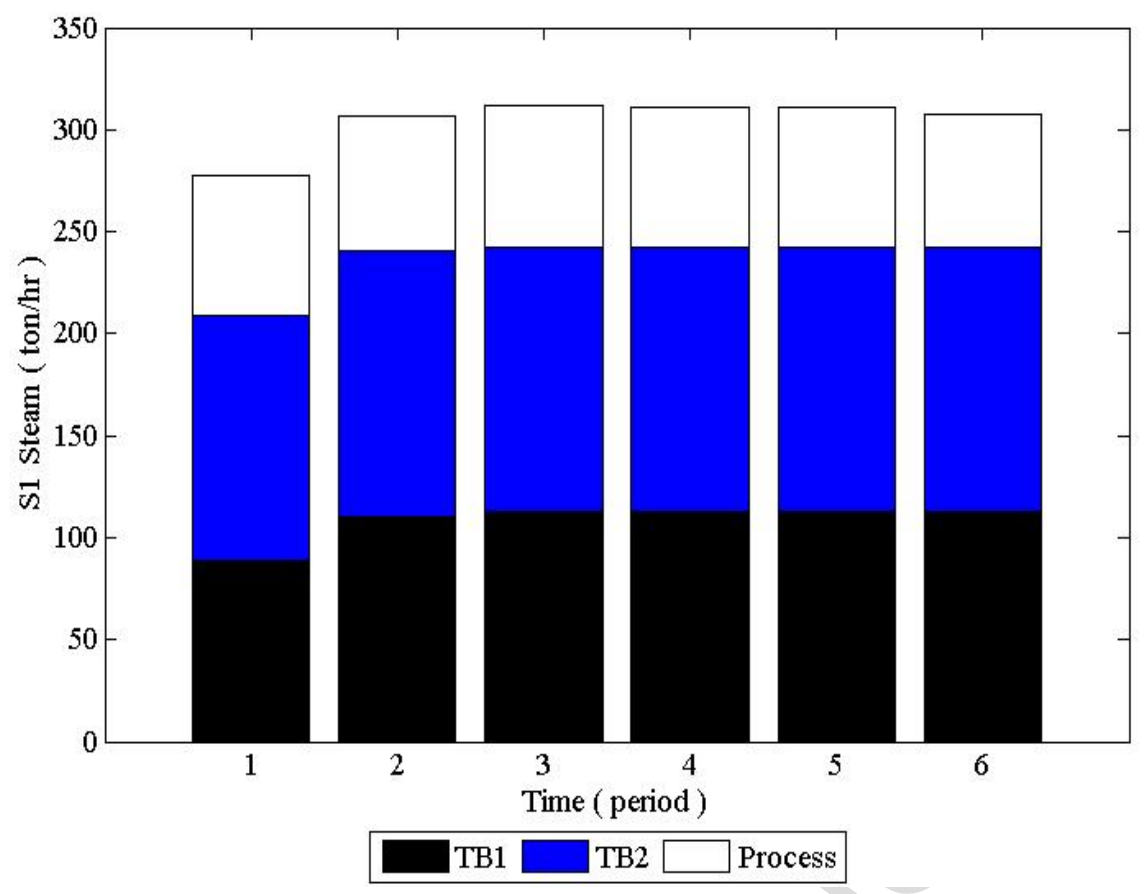

Figure 18 Optimal distribution of HP steam S1 in production units and steam turbines 
Table 1 Data for boilers

\begin{tabular}{ccccccc}
\hline Boiler & $\begin{array}{c}\text { Efficiency } \\
\eta_{i}\end{array}$ & $\begin{array}{c}F_{i, B F G}^{\max } \\
\left(\mathrm{km}^{3} / \mathrm{hr}\right)\end{array}$ & $\begin{array}{c}F_{i, C O G}^{\max } \\
\left(\mathrm{km}^{3} / \mathrm{hr}\right)\end{array}$ & $\begin{array}{c}F_{i, H P}^{\min } \\
(\mathrm{ton} / \mathrm{hr})\end{array}$ & $\begin{array}{c}F_{i, H P}^{\max } \\
(\mathrm{ton} / \mathrm{hr})\end{array}$ & $\begin{array}{c}H V_{i}^{\min } \\
\left(\mathrm{kJ} / \mathrm{m}^{3}\right)\end{array}$ \\
\hline B1 & 0.89 & 40 & 6 & 0 & 35 & 3500 \\
B2 & 0.92 & 40 & 6 & 0 & 35 & 3500 \\
B3 & 0.84 & 120 & 7 & 0 & 130 & 3500 \\
B4 & 0.86 & 120 & 7 & 0 & 130 & 3500 \\
\hline
\end{tabular}


Table 2 Data for steam turbines, CHP and CDQ units

\begin{tabular}{|c|c|c|c|c|c|c|c|c|c|c|c|}
\hline Turbine & $\begin{array}{c}\text { Efficiency } \\
\eta_{j}\end{array}$ & $\begin{array}{c}F_{j, H P}^{i n, \min } \\
\text { (ton/hr) }\end{array}$ & $\begin{array}{c}F_{j, H P}^{\text {in,max }} \\
\text { (ton/hr) }\end{array}$ & $\begin{array}{c}F_{j, M P}^{\text {out }, \min } \\
\text { (ton/hr) }\end{array}$ & $\begin{array}{c}F_{j, M P}^{\text {out,max }} \\
\text { (ton } / \mathrm{hr} \text { ) }\end{array}$ & $\begin{array}{c}F_{j, L P}^{\text {out,min }} \\
\text { (ton } / \mathrm{hr} \text { ) }\end{array}$ & $\begin{array}{c}F_{j, L P}^{\text {out,max }} \\
\text { (ton/hr) }\end{array}$ & $\begin{array}{l}P_{j}^{\min } \\
(\mathrm{MW})\end{array}$ & $\begin{array}{l}P_{j}^{\max } \\
(\mathrm{MW})\end{array}$ & $\begin{array}{c}D R_{j} \\
(\mathrm{MW} / \mathrm{hr})\end{array}$ & $\begin{array}{c}U R_{j} \\
(\mathrm{MW} / \mathrm{hr})\end{array}$ \\
\hline TB1 & 0.82 & 60 & 130 & 0 & 60 & 0 & 100 & 0 & 25 & 5 & 5 \\
\hline TB2 & 0.85 & 60 & 130 & 0 & 60 & 0 & 100 & 0 & 25 & 5 & 5 \\
\hline
\end{tabular}

\begin{tabular}{|c|c|c|c|c|c|c|c|c|c|c|c|c|}
\hline CHP & $\begin{array}{c}\text { Efficiency } \\
\eta_{k}\end{array}$ & $\begin{array}{c}F_{k, B F G}^{\max } \\
\left(\mathrm{km}^{3} / \mathrm{hr}\right)\end{array}$ & $\begin{array}{c}F_{k, C O G}^{\max } \\
\left(\mathrm{km}^{3} / \mathrm{hr}\right)\end{array}$ & $\begin{array}{l}H V_{k}^{\min } \\
\left(\mathrm{kJ} / \mathrm{m}^{3}\right)\end{array}$ & $\begin{array}{l}F_{k, M P}^{\min } \\
\text { (ton } / \mathrm{hr} \text { ) }\end{array}$ & $\begin{array}{c}F_{k, M P}^{\max } \\
\text { (ton/hr) }\end{array}$ & $\begin{array}{c}F_{k, L P}^{\min } \\
\text { (ton/hr) }\end{array}$ & $\begin{array}{c}F_{k, L P}^{\max } \\
\text { (ton/hr) }\end{array}$ & $\begin{array}{l}P_{k}^{\min } \\
(\mathrm{MW})\end{array}$ & $\begin{array}{l}P_{k}^{\max } \\
(\mathrm{MW})\end{array}$ & $\begin{array}{c}D R_{k} \\
(\mathrm{MW} / \mathrm{hr})\end{array}$ & $\begin{array}{c}U R_{k} \\
(\mathrm{MW} / \mathrm{hr})\end{array}$ \\
\hline CHP 1 & 0.38 & 0 & 130 & 4600 & 0 & 80 & 0 & 110 & 220 & 300 & 20 & 20 \\
\hline CHP 2 & 0.39 & 0 & 130 & 4600 & 0 & 80 & 0 & 110 & 220 & 300 & 20 & 20 \\
\hline
\end{tabular}

\begin{tabular}{|c|c|c|c|c|c|c|c|c|}
\hline CDQ & $\begin{array}{c}\text { Efficiency } \\
\eta_{m}\end{array}$ & $\begin{array}{l}F_{m, H P}^{\min } \\
(\text { ton/hr) }\end{array}$ & $\begin{array}{l}F_{m, H P}^{\max } \\
(\text { ton } / \mathrm{hr})\end{array}$ & $\begin{array}{l}F_{m, H P}^{\min } \\
\text { (ton/hr) }\end{array}$ & $\begin{array}{cc}F_{m, H P}^{\max } & P_{m}^{\min } \\
(\text { ton } / \mathrm{hr}) & (\mathrm{MW})\end{array}$ & $\begin{array}{l}P_{m}^{\max } \\
(\mathrm{MW})\end{array}$ & $\begin{array}{c}D R_{m} \\
(\mathrm{MW} / \mathrm{hr})\end{array}$ & $\begin{array}{c}U R_{m} \\
(\mathrm{MW} / \mathrm{hr})\end{array}$ \\
\hline CDQ1 & 0.73 & 0 & 40 & 0 & 60 & 30 & 5 & 5 \\
\hline CDQ 2 & 0.75 & 0 & 40 & 0 & 60 & 30 & 5 & 5 \\
\hline
\end{tabular}


Table 3 Data for byproduct gas burners in boilers and CHP units

\begin{tabular}{cccccc}
\hline \multirow{2}{*}{ Boilers } & \multicolumn{2}{c}{ Initial number $\left(N 0_{i q}\right)$} & & \multicolumn{2}{c}{ Inlet flow rate per burner $\left(F_{i q}, \mathrm{~km}^{3} / \mathrm{hr}\right)$} \\
\cline { 2 - 3 } \cline { 5 - 6 } & COG & BFG & & COG & BFG \\
\cline { 1 - 2 } \cline { 5 - 6 } B1 & 2 & 4 & & 0.5 & 5 \\
B2 & 2 & 4 & & 0.5 & 5 \\
B3 & 0 & 23 & & 0.5 & 5 \\
B4 & 0 & 23 & & 0.5 & 5 \\
CHP1 & 14 & 16 & & 2 & 10 \\
CHP2 & 14 & 16 & & 2 & 10 \\
\hline
\end{tabular}


Table 4 Minimum and maximum capacities, low, normal and high operational levels in gasholders

\begin{tabular}{llll}
\hline Volume $\left(\mathrm{km}^{3}\right)$ & COG & BFG & LDG \\
\hline Minimum capacity $\left(\operatorname{Inv}{ }_{q}^{\min }\right)$ & 40 & 50 & 15 \\
Low operational inventory level $\left(\operatorname{In} v_{q}^{L}\right)$ & 80 & 140 & 25 \\
Normal operational inventory level $\left(\operatorname{In} v_{q}^{N}\right)$ & 100 & 180 & 40 \\
High operational inventory level $\left(\operatorname{In} v_{q}^{H}\right)$ & 120 & 220 & 55 \\
Maximum capacity $\left(\operatorname{In} \max _{q}\right)$ & 135 & 260 & 70 \\
\hline
\end{tabular}


Table 5 Heating values of byproduct gases, coal, and natural gas, and enthalpy of boiler feed water and steam

\begin{tabular}{cccccc}
\hline Item & COG & BFG & LDG & Natural gas & Coal \\
\hline $\begin{array}{c}\text { Heating } \\
\text { value }\end{array}$ & 18000 & 3500 & 7500 & 35400 & 21800 \\
\hline \multirow{2}{*}{ Item } & Boiler feed & High-pressure & Medium-pressure & Low-pressure \\
& water & steam S1 & steam S2 & steam S3 \\
\hline Enthalpy & 105.38 & 3300 & 3100 & 2930 \\
\hline
\end{tabular}

Unit for heating values of byproduct gases is $\mathrm{kJ} / \mathrm{m}^{3}$

Unit for heating value of coal is $\mathrm{kJ} / \mathrm{kg}$

Enthalpy unit is $\mathrm{kJ} / \mathrm{kg}$ 
Table 6 maximum imported and exported power, penalty coefficients and economic data for the industrial example

\begin{tabular}{|c|c|}
\hline Item & Value \\
\hline Maximum imported power $\left(P_{t}^{i m p, \max }, \mathrm{MW}\right)$ & 130 \\
\hline Maximum exported power $\left(P_{t}^{\exp , \max }, \mathrm{MW}\right)$ & 100 \\
\hline Penalty coefficient for gas emission $\left(W_{q}^{\text {emission }}, ¥ / \mathrm{m}^{3}\right.$ ) & \\
\hline Penalty coefficient for violation of high operational level $\left(W_{q}^{H}, ¥ / \mathrm{m}^{3}\right)$ & 10 \\
\hline Penalty coefficient for violation of low operational level $\left(W_{q}^{L}, ¥ / \mathrm{m}^{3}\right)$ & 5 \\
\hline Penalty coefficient for deviation below normal operation $\left(W_{q}^{d^{-}}, ¥ / \mathrm{m}^{3}\right)$ & 1 \\
\hline Penalty coefficient for deviation above normal operation $\left(W_{q}^{d^{+}}, ¥ / \mathrm{m}^{3}\right)$ & 1 \\
\hline Penalty coefficient for burner switches ( $W_{q}^{S W}, ¥ /$ switch) & 800 \\
\hline Penalty coefficient for simultaneous switches of two burners $\left(W_{q}^{2 S}, ¥ /\right.$ instance $)$ & 100 \\
\hline Penalty coefficient for simultaneous switches of three burners $\left(W_{q}^{3 S}, ¥ /\right.$ instance $)$ & 200 \\
\hline Maintenance cost for boilers $\left(C_{i}^{M}, ¥ /\right.$ ton $)$ & 6 \\
\hline Maintenance cost for turbines $\left[C_{j}^{P M}, ¥ /(\mathrm{kW} \cdot \mathrm{h})\right]$ & 0.06 \\
\hline Maintenance cost of CHP units $\left[C_{k}^{P M}, ¥ /(\mathrm{kW} \cdot \mathrm{h})\right]$ & 0.08 \\
\hline Maintenance cost of waste heat and energy recovery units $\left[C_{m}^{P M}, ¥ /(\mathrm{kW} \cdot \mathrm{h})\right]$ & 0.06 \\
\hline Coal purchase cost $\left(C_{\text {coal }}, ¥ /\right.$ ton $)$ & 500 \\
\hline Natural gas purchase cost $\left(C_{\text {natural gas }}, ¥ / \mathrm{m}^{3}\right)$ & 3.5 \\
\hline Electricity purchase cost $\left[C_{t}^{i m p}, ¥ /(\mathrm{kW} \cdot \mathrm{h})\right]$ & 0.5 \\
\hline Electricity sale price $\left[C_{t}^{e x p}, ¥ /(\mathrm{kW} \cdot \mathrm{h})\right]$ & 0.2 \\
\hline
\end{tabular}


Table 7 Byproduct gas generation rates and steam and power demands and waste heat and energy recovery amounts in periods

\begin{tabular}{|c|c|c|c|c|c|c|c|c|c|}
\hline \multirow[t]{2}{*}{ Period } & \multicolumn{3}{|c|}{$\begin{array}{l}\text { Byproduct Gases } \\
\qquad\left(\mathrm{km}^{3} / \mathrm{hr}\right)\end{array}$} & \multicolumn{2}{|c|}{$\begin{array}{c}\text { Waste heat and } \\
\text { energy recovery } \\
(\mathrm{MJ})\end{array}$} & \multirow[t]{2}{*}{$\begin{array}{l}\text { Power } \\
(\mathrm{MW})\end{array}$} & \multicolumn{3}{|c|}{$\begin{array}{l}\text { Steam } \\
\text { (ton/hr) }\end{array}$} \\
\hline & BFG & $\mathrm{COG}$ & LDG & CDQ1 & CDQ2 & & S1 & $\mathrm{S} 2$ & S3 \\
\hline 1 & 1514 & 179.50 & 92 & 138965 & 247400 & 698 & 68 & 233 & 255 \\
\hline 2 & 1523 & 175.50 & 84 & 148852 & 244365 & 690 & 66 & 234 & 253 \\
\hline 3 & 1525 & 177.70 & 82 & 141945 & 252940 & 685 & 60 & 247 & 253 \\
\hline 4 & 1505 & 177.80 & 81 & 150774 & 259550 & 691 & 68 & 244 & 257 \\
\hline 5 & 1522 & 175.70 & 89 & 154864 & 266540 & 707 & 68 & 234 & 250 \\
\hline 6 & 1508 & 176.80 & 80 & 155955 & 272540 & 709 & 65 & 228 & 255 \\
\hline
\end{tabular}


Table 8 COG demands for production units in time periods

\begin{tabular}{ccccccc}
\hline Period & $\begin{array}{c}\text { Sintering } \\
\text { furnace }\end{array}$ & $\begin{array}{c}\text { 1\#-2\# } \\
\text { Coke oven }\end{array}$ & $\begin{array}{c}\text { Pelletizing } \\
\text { plant }\end{array}$ & $\begin{array}{c}\text { steelmaking } \\
\text { mill }\end{array}$ & $\begin{array}{c}\text { Cold } \\
\text { rolling } \\
\text { mills }\end{array}$ & Others \\
\hline 1 & 3 & 25 & 12 & 14 & 30 & 9.3 \\
2 & 3 & 27 & 12 & 14 & 32 & 9.3 \\
3 & 3 & 26 & 12 & 14 & 31 & 10 \\
4 & 3 & 26 & 12 & 14 & 32 & 9.3 \\
5 & 3 & 27 & 12.3 & 14 & 36 & 9.4 \\
6 & 3 & 26 & 13 & 13.5 & 34 & 9.3 \\
\hline
\end{tabular}

Demand unit is $\mathrm{km}^{3}$ 
Table 9 Demands of BFG, LDG and energy for production units in time periods

\begin{tabular}{|c|c|c|c|c|c|}
\hline \multirow[b]{2}{*}{ Period } & \multicolumn{3}{|c|}{ BFG } & \multirow{2}{*}{$\frac{\text { LDG }}{\text { Shaft kiln }}$} & \multirow{2}{*}{$\begin{array}{c}\text { Energy } \\
\text { Hot strip }\end{array}$} \\
\hline & Hot stoves & $\begin{array}{c}3 \#-4 \# \text { Coke } \\
\text { oven }\end{array}$ & Others & & \\
\hline 1 & 575 & 263 & 44 & 47 & 1062 \\
\hline 2 & 562 & 261 & 38 & 46 & 932 \\
\hline 3 & 563 & 263 & 33 & 45 & 991 \\
\hline 4 & 571 & 258 & 27 & 45 & 918 \\
\hline 5 & 583 & 255 & 41 & 49 & 949 \\
\hline 6 & 581 & 263 & 43 & 38 & 1042 \\
\hline
\end{tabular}

BFG and LDG demand unit is $\mathrm{km}^{3}$

Energy demand unit is MJ 
Table 10 Comparative results from the proposed model and actual operation

\begin{tabular}{lrr}
\hline Item & $\begin{array}{r}\text { Actual } \\
\text { Operation }\end{array}$ & $\begin{array}{r}\text { Proposed } \\
\text { Model }\end{array}$ \\
\hline Coal cost $(¥)$ & 858,560 & 797,831 \\
Natural gas cost (¥) & 0 & 0 \\
Penalty for byproduct gas emissions (¥) & 0 & 0 \\
Penalty for violation of high levels in gasholders (¥) & 0 & 0 \\
Penalty for violation of low levels in gasholders (¥) & 0 & 0 \\
Penalty for deviation from normal levels in gasholders $(¥)$ & 16,600 & 4,933 \\
Penalty for burner switches (¥) & 36,800 & 30,900 \\
Equipment maintenance cost $(¥)$ & 316,197 & 328,284 \\
Electricity purchase cost $(¥)$ & 63,404 & 48,443 \\
Electricity sale revenue $(¥)$ & 0 & 0 \\
Total cost $(¥)$ & $1,291,562$ & $1,210,391$ \\
\hline
\end{tabular}


Table 11 The number of burners whose status is on in boilers obtained by optimal calculation

\begin{tabular}{|c|c|c|c|c|c|c|c|c|c|c|c|c|}
\hline \multirow{2}{*}{ Period } & \multicolumn{2}{|c|}{ B1 } & \multicolumn{2}{|c|}{$\mathrm{B} 2$} & \multicolumn{2}{|c|}{ B3 } & \multicolumn{2}{|c|}{ B4 } & \multicolumn{2}{|r|}{ CHP1 } & \multicolumn{2}{|c|}{ CHP2 } \\
\hline & BFG & $\mathrm{COG}$ & BFG & $\mathrm{COG}$ & BFG & $\mathrm{COG}$ & BFG & $\mathrm{COG}$ & BFG & $\mathrm{COG}$ & BFG & $\mathrm{COG}$ \\
\hline 0 & 4 & 2 & 4 & 2 & 23 & 0 & 23 & 0 & 16 & 14 & 16 & 14 \\
\hline 1 & 4 & 2 & 4 & 2 & 23 & 1 & 23 & 2 & 14 & 12 & 13 & 12 \\
\hline 2 & 6 & 2 & 5 & 3 & 24 & 3 & 24 & 5 & 14 & 12 & 13 & 12 \\
\hline 3 & 6 & 2 & 5 & 3 & 24 & 3 & 24 & 6 & 14 & 12 & 13 & 12 \\
\hline 4 & 6 & 2 & 5 & 3 & 24 & 3 & 24 & 6 & 14 & 12 & 13 & 12 \\
\hline 5 & 6 & 2 & 5 & 3 & 24 & 3 & 24 & 6 & 13 & 12 & 12 & 11 \\
\hline 6 & 6 & 2 & 5 & 3 & 24 & 3 & 24 & 6 & 13 & 12 & 11 & 10 \\
\hline
\end{tabular}


Table 12 Steam and power generation, coal consumption, gasholder level and imported power from the actual operation

\begin{tabular}{|c|c|c|c|c|c|c|c|}
\hline Equipment & Item & $\mathrm{T} 1$ & $\mathrm{~T} 2$ & $\mathrm{~T} 3$ & $\mathrm{~T} 4$ & $\mathrm{~T} 5$ & T6 \\
\hline B1 & S1 (ton/hr) & 35 & 35 & 35 & 35 & 35 & 34 \\
\hline $\mathrm{B} 2$ & S1 (ton/hr) & 33 & 31 & 34 & 33 & 33 & 31 \\
\hline B3 & $\mathrm{S} 1$ (ton/hr) & 115 & 120 & 125 & 125 & 125 & 125 \\
\hline B4 & $\mathrm{S} 1$ (ton/hr) & 110 & 117 & 125 & 128 & 128 & 128 \\
\hline \multirow[t]{3}{*}{ TB1 } & $\mathrm{S} 2$ (ton/hr) & 46 & 46 & 45 & 45 & 45 & 45 \\
\hline & S3 (ton/hr) & 69 & 74 & 80 & 80 & 80 & 80 \\
\hline & Power (MW) & 18 & 18 & 20 & 20 & 20 & 20 \\
\hline \multirow[t]{3}{*}{ TB2 } & $\mathrm{S} 2(\mathrm{ton} / \mathrm{hr})$ & 43 & 43 & 42 & 42 & 42 & 42 \\
\hline & S3 (ton/hr) & 67 & 74 & 83 & 86 & 86 & 86 \\
\hline & Power (MW) & 19 & 19 & 21 & 21 & 21 & 21 \\
\hline \multirow[t]{4}{*}{ CHP1 } & Coal (ton/hr) & 126.25 & 126.25 & 131 & 131 & 135 & 132 \\
\hline & S2 (ton/hr) & 37 & 37 & 42 & 42 & 40 & 37 \\
\hline & $\mathrm{S} 3$ (ton/hr) & 25 & 25 & 25 & 25 & 25 & 25 \\
\hline & Power (MW) & 290 & 290 & 290 & 300 & 300 & 300 \\
\hline \multirow[t]{4}{*}{$\mathrm{CHP} 2$} & Coal (ton/hr) & 138 & 138 & 139 & 139 & 145.5 & 142.25 \\
\hline & $\mathrm{S} 2($ ton/hr) & 37 & 37 & 42 & 42 & 40 & 37 \\
\hline & S3 (ton/hr) & 62 & 62 & 62 & 62 & 62 & 62 \\
\hline & Power (MW) & 290 & 290 & 290 & 290 & 290 & 290 \\
\hline \multirow[t]{3}{*}{ CDQ1 } & $\mathrm{S} 1$ (ton/hr) & 0 & 0 & 0 & 0 & 0 & 0 \\
\hline & $\mathrm{S} 2$ (ton/hr) & 37 & 37 & 40 & 40 & 37 & 37 \\
\hline & Power (MW) & 28 & 28 & 27 & 27 & 27 & 27 \\
\hline \multirow[t]{3}{*}{ CDQ2 } & $\mathrm{S} 1$ (ton/hr) & 0 & 0 & 0 & 0 & 0 & 0 \\
\hline & $\mathrm{S} 2($ ton $/ \mathrm{hr})$ & 33 & 34 & 36 & 33 & 30 & 30 \\
\hline & Power (MW) & 22 & 22 & 22 & 22 & 23 & 23 \\
\hline BFG Gasholder & $\mathrm{BFG}\left(\mathrm{km}^{3}\right)$ & 179.3 & 178.4 & 180 & 178.5 & 179.5 & 178.8 \\
\hline COG Gasholder & $\operatorname{COG}\left(\mathrm{km}^{3}\right)$ & 99.4 & 100 & 100 & 98.8 & 99.6 & 98.7 \\
\hline LDG Gasholder & $\operatorname{LDG}\left(\mathrm{km}^{3}\right)$ & 42.2 & 41.5 & 40 & 38.7 & 38.6 & 39.2 \\
\hline Imported power & Power (MW) & 29.5 & 18.6 & 15 & 11.5 & 24.1 & 28.2 \\
\hline
\end{tabular}


Table 13 The number of burners whose status is on in boilers from the actual operation

\begin{tabular}{|c|c|c|c|c|c|c|c|c|c|c|c|c|}
\hline \multirow{2}{*}{ Period } & \multicolumn{2}{|c|}{ B1 } & \multicolumn{2}{|c|}{ B2 } & \multicolumn{2}{|c|}{ B3 } & \multicolumn{2}{|c|}{ B4 } & \multicolumn{2}{|r|}{ CHP1 } & \multicolumn{2}{|c|}{ CHP2 } \\
\hline & BFG & $\mathrm{COG}$ & BFG & $\mathrm{COG}$ & BFG & $\mathrm{COG}$ & BFG & $\mathrm{COG}$ & BFG & $\mathrm{COG}$ & BFG & $\mathrm{COG}$ \\
\hline 0 & 4 & 2 & 4 & 2 & 23 & 0 & 23 & 0 & 16 & 14 & 16 & 14 \\
\hline 1 & 5 & 3 & 5 & 5 & 24 & 3 & 23 & 3 & 13 & 12 & 18 & 10 \\
\hline 2 & 5 & 3 & 5 & 4 & 24 & 6 & 23 & 5 & 13 & 12 & 18 & 10 \\
\hline 3 & 6 & 2 & 5 & 5 & 24 & 8 & 24 & 7 & 16 & 10 & 18 & 10 \\
\hline 4 & 6 & 2 & 5 & 3 & 24 & 8 & 24 & 8 & 16 & 10 & 16 & 10 \\
\hline 5 & 6 & 2 & 5 & 3 & 24 & 8 & 24 & 8 & 17 & 10 & 16 & 9 \\
\hline 6 & 6 & 2 & 5 & 3 & 24 & 8 & 24 & 8 & 16 & 9 & 15 & 9 \\
\hline
\end{tabular}

